\title{
Characterizing Lake Bottom Sediments Using Marine Geophysical Tools
}

\author{
Abdulrahman M. Alotaibi1,2, Stanley Nwokebuihe², Evegniy Torgashov², Adel Elkrry², \\ Neil Anderson ${ }^{2}$
}

${ }^{1}$ King Abdulaziz City for Science and Technology, Riyadh, KSA

${ }^{2}$ University of Missouri for Science and Technology, Rolla, USA

Email: Alotaibiaotaibi@kacst.edu.sa, scnqq3@mst.edu, Evgeniy@mst.edu, ame4k4@mst.edu, nanders@mst.edu

How to cite this paper: Alotaibi, A.M., Nwokebuihe, S., Torgashov, E., Elkrry, A. and Anderson, N. (2019) Characterizing Lake Bottom Sediments Using Marine Geophysical Tools. International Journal of Geosciences, 10, 328-350.

https://doi.org/10.4236/iig.2019.103019

Received: January 27, 2019

Accepted: March 26, 2019

Published: March 29, 2019

Copyright $\odot 2019$ by author(s) and Scientific Research Publishing Inc. This work is licensed under the Creative Commons Attribution International License (CC BY 4.0).

http://creativecommons.org/licenses/by/4.0/

\begin{abstract}
Missouri is a state with rich karst terrain. Geotechnical evaluation of foundation design for bridges and dams requires an understanding of the characteristics of subsurface geological environment, including sediments, bedrock and benthic habitat. It is crucial that the community empowers itself with the knowledge of the karst system's characteristics in order to potentially use it as a source of water and drainage, but also to avoid the disaster of building constructions too close to vulnerable land on top of massive karst caverns. Electrical resistivity tomography profiling (underwater cables), and continuous resistivity profiling (towed cable) surveys were conducted to characterize the lake sediments (rock and soil) beneath the man-made Little Prairie Lake, in Central of Missouri State, United States. Electrical resistivity (with marine cables and towed cable) was used to determine variability in the lithology and thickness of sediments (soil and rock) beneath the lake with conjunction of echo sounder in order to calculate water depth. Side scan sonar was used to map the variations in the lithology/nature of exposed lakebed sediments and to locate the potential hazard of trees. On land, electrical resistivity tomography was used with multi-channel analysis of surface wave method to determine sediments, joints, and the depth of bedrock. Analyses of the acquired data revealed the location and orientation of the original stream channels (prior to the construction of the earth fill dam). Underwater electrical resistivity tomography and continuous resistivity profiling determined joints, sediments, and bedrock underneath water bodies. Integrated marine geophysical tools help to evaluate the subsurface prior to any construction project (dam or bridge), are useful in determining the characteristics of lithology (fractured rock, intact rock and soil), and make it possible to map benthic habitat and the submerged potential hazards of trees on the lakebed as well as accurately measuring water depth.
\end{abstract}




\section{Keywords}

Marine Electrical Resistivity, Side Scan Sonar, Characterize Sediments, Water

Depth, Fractures, Missouri

\section{Introduction}

Missouri state is rich with karst terrain network and is known as the Cave State. Cave systems, sinkholes, and underground voids underneath the larger portion of Southern Missouri are resulted of dissolution of carbonate rocks [1] [2] [3]. Much is known about Missouri's karst terrains, but not quite enough to provide building projects with the assurance of starting construction projects without turning to geological and geophysical study first.

[4] documented 97 catastrophic collapses in Missouri karst terrain areas. Unfortunately, due to the complex cave networks underground, Missouri is one of the prime sites for collapse sinkholes, making the threat of following landslides very real, especially in more rugged, hilly terrain. In fact, over the period from 1930 to 1975 , there were 51 collapse sinkholes reported by natural causes, which are the most dangerous because of the lack of planning and preparation for the aftermath [5]. Some of these sinkholes reached up to $90 \mathrm{~m}$ diameter, a massive collapse that caused incredible damage [6]. Such collapses have the potential to create a domino effect of surrounding landslides as the terrain adjusts. Moreover, there were also 46 manmade-generated collapses, 24 altered drainage-related collapses, and three highway construction-caused collapse sinkholes.

Geotechnical evaluation of foundation design for bridges and dams requires an understanding of the characteristics of subsurface geological environment. The presence of fractures within bedrock and karst voids and caverns causes instability in load-bearing compared to massive bedrock [7]. This forces developers to take extra precautions in the planning, subsurface investigation, analysis and design, and development of such projects in order to avoid catastrophes [6].

Integrated land and over water bodies geophysical tools have been conducted in several studies [8]-[16].

This work is an integrated study using several marine and land geophysical tools to help provide knowledge of the geological materials of the lake for both construction and conservation efforts to empower strategies for working in the region. In addition, utilizing acoustic and electrical resistivity methods in mapping karst features beneath and adjacent to Little Prairie Lake, maps subsurface lithology, soil and structural features of the Lake and its proximity, mapping solution-widened joints and their trends, mapping benthic habitats, and maps the variable water depth, with the goal of identifying abandoned stream channels and paleochannels infill.

\section{Topography}

Little Prairie Lake is a man-made, located in Dillon, Phelps County, Missouri at 
latitude $37.9950419^{\circ} \mathrm{N}$, and longitude $91.6901571^{\circ} \mathrm{W}$, and an elevation of $1032 \mathrm{ft}$. (asl), as displayed in (Figure 1). The Lake is surrounded by forests bordered in the southeast section by prairie.

The study area is characterized by undulating topography at the vicinity of the lake, and by isolated knobs and hills in its elevated parts. Two main streams traverse the study area, and convolve close to the foot of the dam in a V-shaped sign, pointing to the northwest. The outflow of the lake waters is maintained through a spillway that diverts water into the Bourbeuse River (Figure 2) [18].

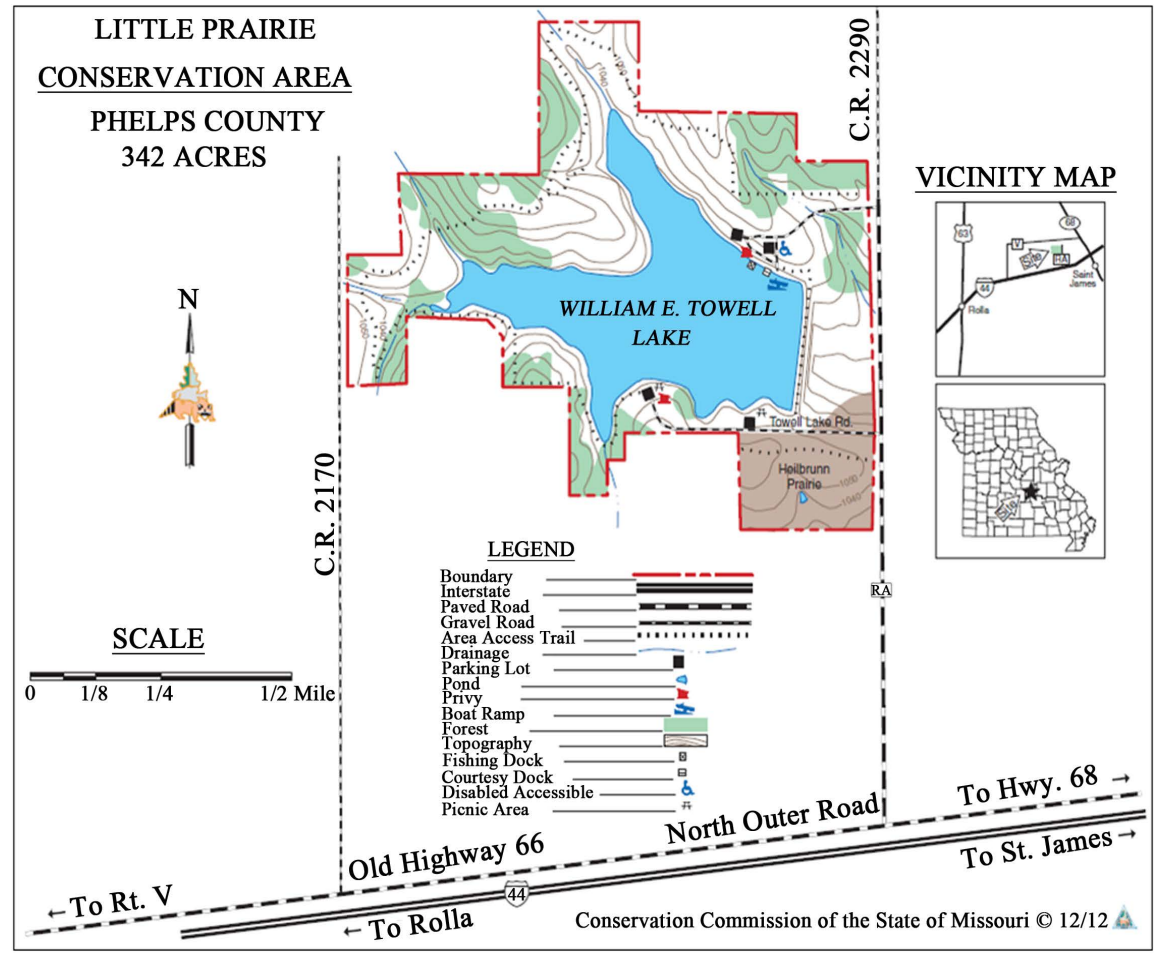

Figure 1. Map of study area [17].

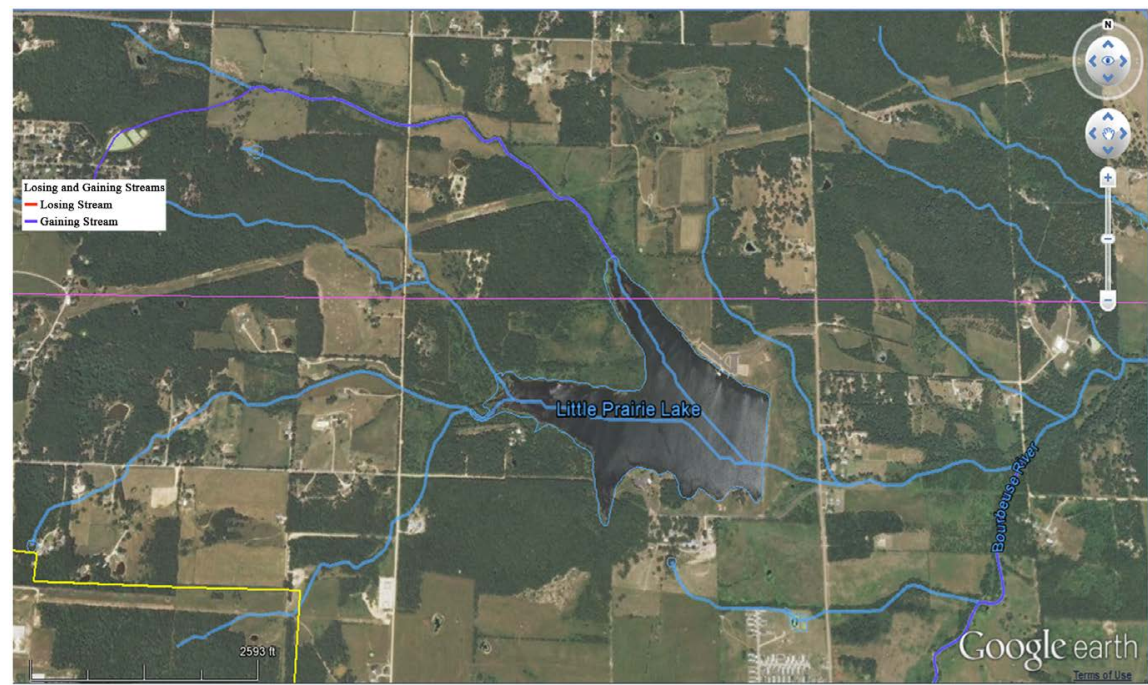

Figure 2. Stream channels of Little Prairie Lake [19]. 


\section{Geological Setting}

Soils in Missouri State are divided into two halves from east to west approximately along Interstate 70 highway where each half consists of series of blocks of different soil types, originally derived from glacial deposits. The northern half is composed of fewer than 100 feet of glacial deposits of clay, silt, sand, gravel, and particulate earth material, and the southern half, which includes Phelps County and Little Prairie Lake, is composed of cherty-clay residuum and colluvium derived mostly from shale and clay [20]. The soil of the lake area is sandy in the areas underpinned by Jefferson City Sandstone and varies in depth between 0 - 35 feet.

The oldest exposed bedrock formations in Phelps County are Gasconade, followed by Roubidoux, then Jefferson City-Cotter. These formations are capped by Pennsylvanian system deposits of $\sim 1$ to 2 feet thick. The regional dipping is generally $2^{\circ}$ to $3^{\circ}$ towards the north and northwest [20].

The Gasconade Formation varies in thickness between 260 and 330 feet and consists of massive beds of brown to light gray dolomite, mixed with white to gray chert (Figure 3). The thickness of the Roubidoux Formation is 95 to 150 feet, characterized by brown to brownish-red sandy dolomite, cherty dolomite, and sandstone [21] that outcrops as sandstone and sandy dolomite in the exposed areas of Phelps County, and is marked by the existence of course sandstone fragments and chert on the surface. The Jefferson City-Cotter Formation is gray to brown dolomite intermingled with chert, sandstone, and shale layers $\sim 125$ to 200 feet thick [21]. These formations are often buried by sandy soils, leaving scarce scattered outcrops visible on the surface. The upper most formation of the Pennsylvanian consists of clay and sandstone, located in the northern

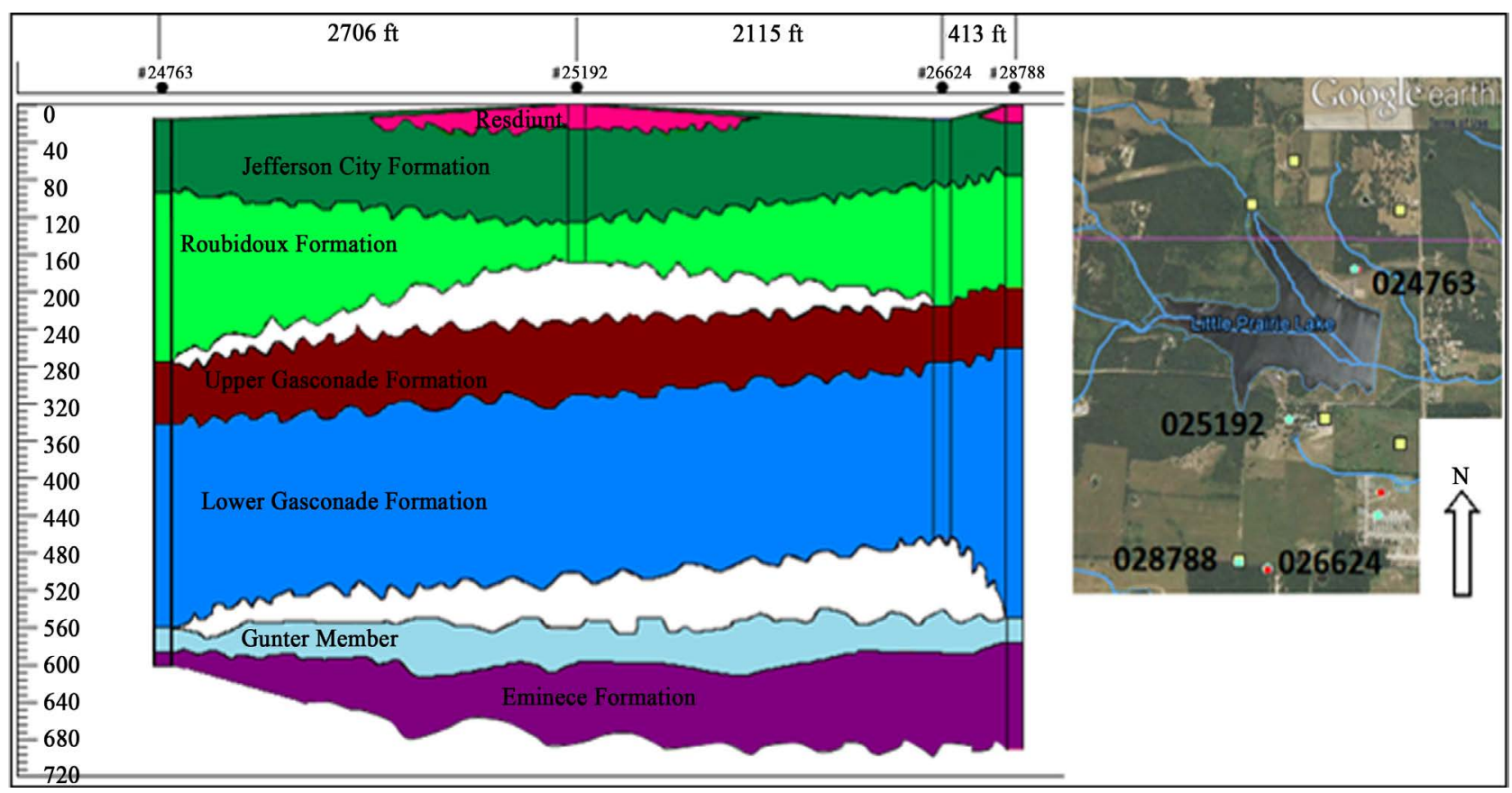

Figure 3. Stratigraphy in the study area. 
parts of Phelps County. These clay deposits exhibit a white and purple color whenever they exist, especially when they are encountered along areas dominated by sandstone and close to uplands.

Although Missouri is the proximity of the infamous New Madrid seismically active zone, the study area of Little Prairie Lake is embedded by minor local faults trending NW-SE that are geologically stable and have no recent movement records (Figure 4) [19].

The Little Prairie Lake falls within the Salem Plateau Uplands, dominated by Pennsylvanian deposits and topped by Ordovician Jefferson City Dolomites.

The Pennsylvanian deposits consist of relatively watertight, medium to massive beds of dolomite. The deposits exhibit different properties, exemplified by silty-loam on flood plains, and silt-loam/silty-clay on weathered slopes [18].

Sinkholes remain the most common topographic features in Phelps County, and they are more located in the southern and southeastern parts of the county where the Roubidoux Formation is deeply weathered, a formation indicative of underlying bedrock weathering, and the existence of incised joints and caves [20].

\section{Methodology}

\subsection{Shallow Marine Acoustic Methods}

Acoustic tools (e.g. echo sounder and side scan sonar) typically measure the amplitude and travel time of the acoustic wave that reflects from water bottom and other objects on lakebed (Figure 5) to map water depth and habitat map.

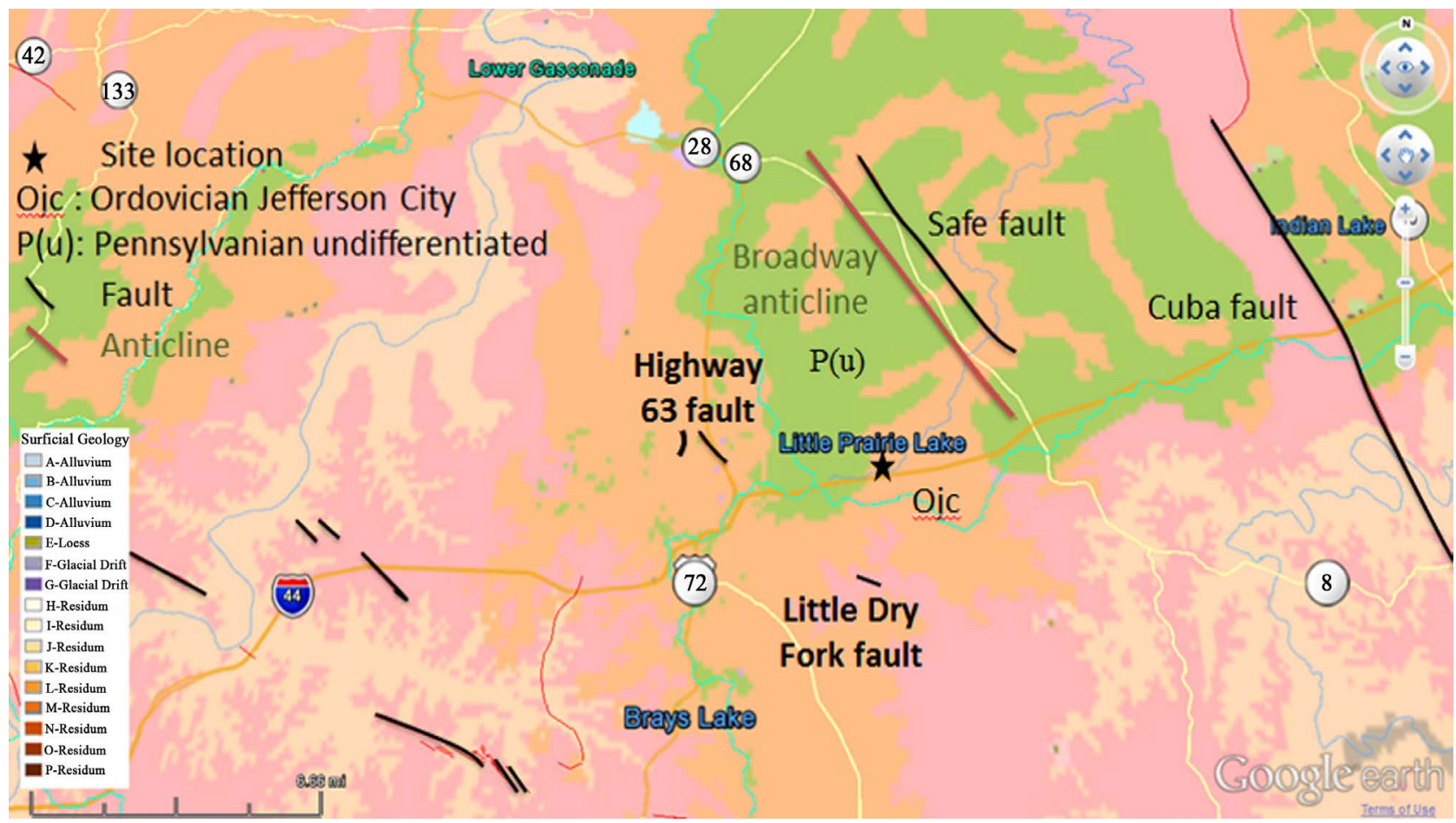

Figure 4. Geological map of study area [20]. 


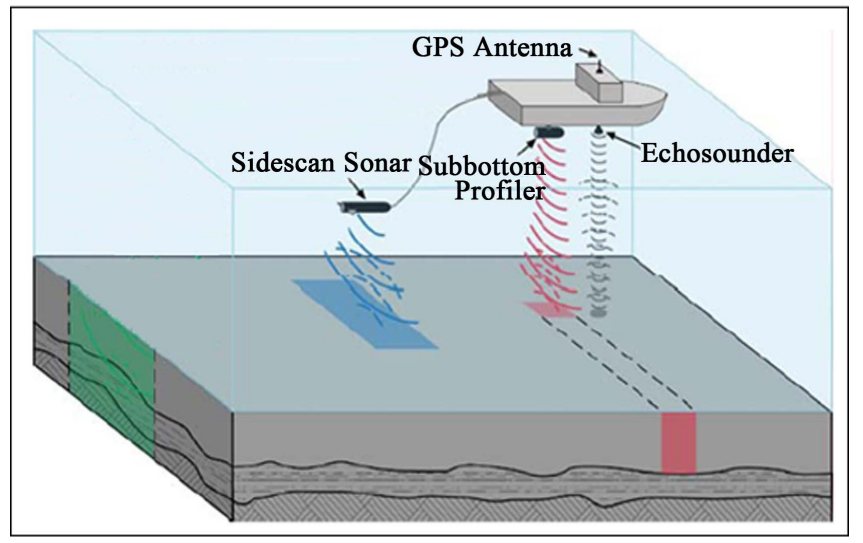

Figure 5. Acoustical geophysical methods for over-water surveys (modified after [22]).

The echo sounder uses high frequency ranges (fathomer) to acquire measurements. Acoustic pulses are transmitted into water in a vertical single wave at frequencies between $24 \mathrm{kHz}$ and $340 \mathrm{kHz}$ and determine objects on the water bottom [23]. The measurement of depth is acquired by measuring time intervals between emitted sounds and returning, the velocity of water is known as approximately $4500 \mathrm{ft} / \mathrm{sec}$ [24].

Side scan sonar emits a wide, fan-shaped high frequency of acoustic beams on both sides of the boat and perpendicular to the boat track line with several hundred feet coverage using a "torpedo-like tow fish" dragged through the water. Acoustic beams create images large areas of lakebed floor and record the changes of the amplitude of objects [25]. Side scan sonar is an efficient tool to determine benthic habitats, pipes, and boulders.

\subsection{Electrical Resistivity Tomography Methods}

This technique works by injecting electrical current into land and lakebed sediments as well as measures the resulting potential difference within sediment material and determine conductivity change and saturation level of deposits (Figure 6). Electrical resistivity tomography methods further identify depressions and voids in bedrock, as well as obtain the apparent resistivity, which exhibits low values in saturated media and cavernous material, and higher values in dense rock and air-filled voids [26]; [27]; [28].

An apparent resistivity $\rho_{\mathrm{a}}$ is determined by measuring potential difference $\Delta V$ at a different couple of electrodes' spacing:

$$
\rho_{a}=k \Delta V / I
$$

where $K$ is a geometric factor of array that we used.

The current study comprises both land and water that requires the use of a subset of electrical resistivity method to be applied to marine environment. Continuous Resistivity Profiling (CRP) was introduced to generate 2D continuous profiles using data collected from eight channels every few seconds via towed electrodes on the water's surface without the need to set them up after every measurement Figure 7. 


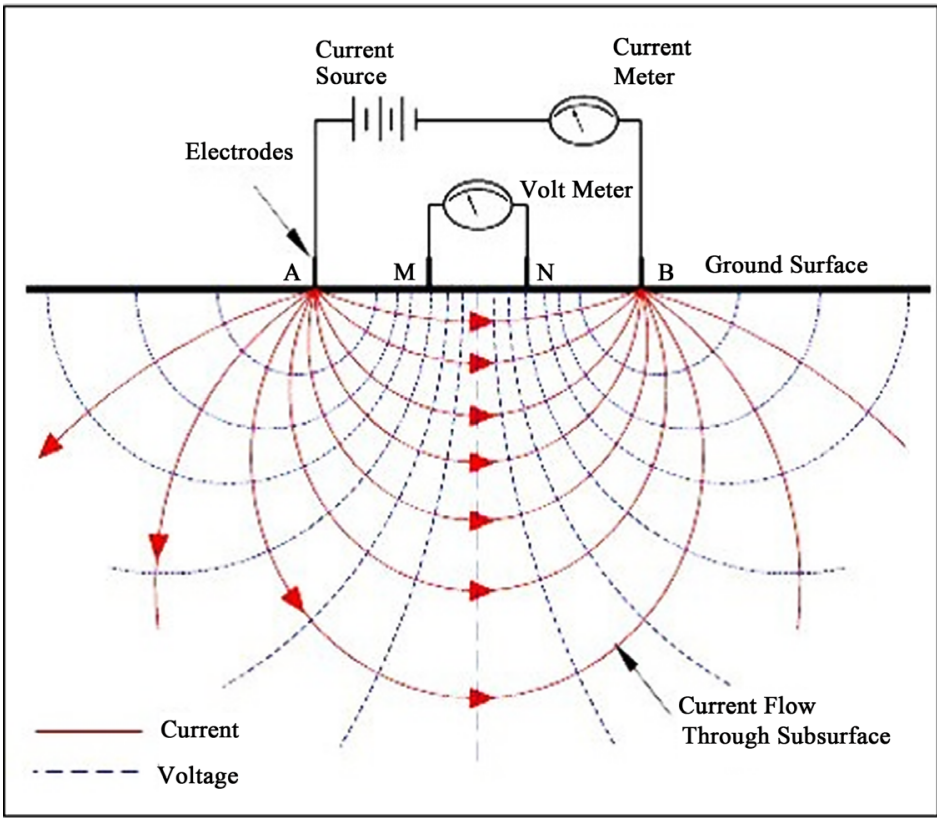

Figure 6. The basic concept of DC resistivity measurements [29].

2 Dimensional Resistivity Profiling: Dipole-dipole Array

$\square \quad$ Electrode Location

- Apparent Resistivity Plotting Location

(I) Transmitted Current

(V) Measured Voltage Gradient

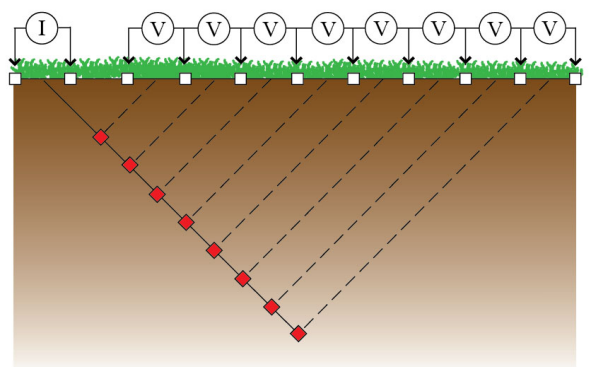

Figure 7. Sample setup of marine survey: an array of electrodes towed behind a boat [26].

\section{Geophysical Data Acquisition}

Acoustic and electrical resistivity methods require a specific procedure in order to produce the most reliable data that can be used in mapping. Due to the nature of the equipment and the type of readings produced, each method requires a separate consideration in regards to how wide the survey lines are in order to avoid overlapping areas or missing gaps on the lake basin.

Echo sounder typically used with CRP equipment to record the water depth of the study area.

Echo sounder equipment contains skimmer echo sounder sensor with 83 and $200 \mathrm{KHz}$ (Figure 8), connected to Lowrance hds 10 GPS and External GPS LGC-4000-Baja antenna. The frequency that was used throughout the context of this survey was $83 \mathrm{KHz}$. 


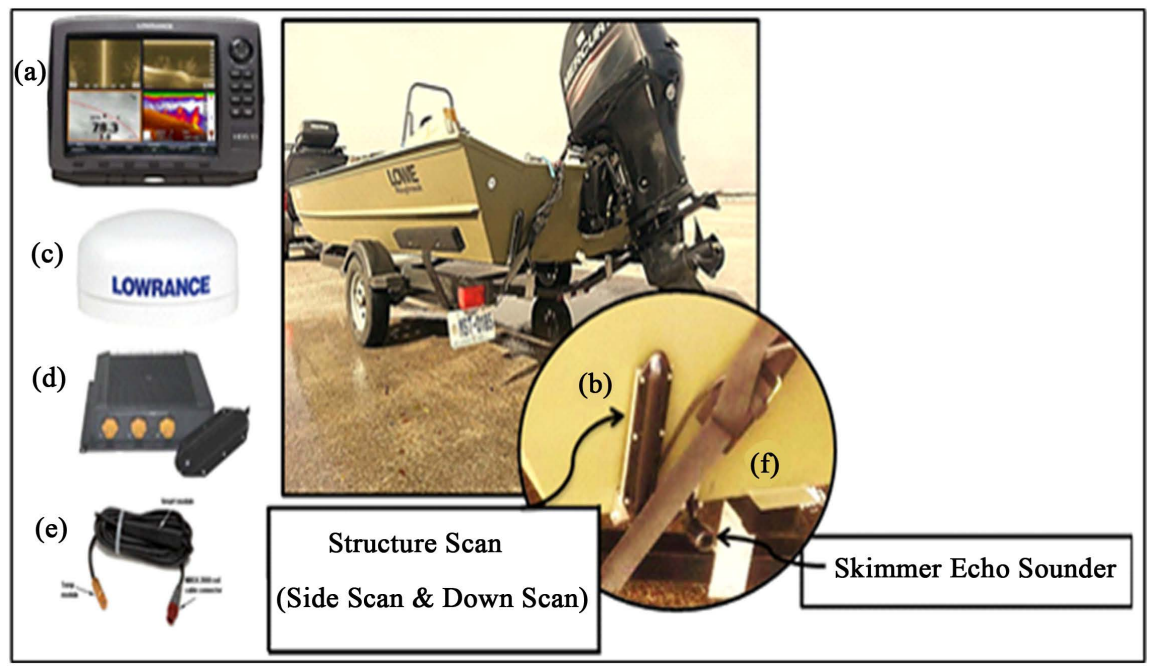

Figure 8. Acoustic equipment. (a) Lowrance HDS-10 Gen2 Fish finder/Chart plotter; (b) Structure Scan (downscan and sidescan) transducers; (c) External GPS LGC-4000-Baja; (d) Structure Scan accessories; (e) Lowrance EP-80R temperature sensor; (f) Skimmer echo sounder.

For side scan sonar survey, two dataset were gathered to cover the entire area of the lake, except the areas that had trees or shallow water, which were difficult to access (Figure 9). Thus, two separate passes were planned carefully so that they made up for any inconsistencies or potential gaps within the data on the first go-round. The total range of beam coverage was 160 feet.

Electrical resistivity Tomography on land (ERT1 and ERT 2), underwater electrical resistivity (ERT3. ERT4, ERT5), and towed cable data with different electrode spacing were acquired using AGI Super Sting R8 unit with cable length of 560 feet and $10 \mathrm{ft}$ electrode spacing (Figure 10) in this study. The water depth was recorded along the electrical resistivity tomography cable.

Four profiles of the multi-channel analysis of surface wave method (MASW) were acquired on land and over electrical resistivity profiles to determine the top of bedrock (Figure 11).

The equipment and tools used in the data acquisition were as follows: main connection unit (Seistronix), source (hammer $10 \mathrm{lb}$.), Receiver (24 Geophone Low-frequency (e.g., 4.5-Hz), and laptop.

In continuous resistivity profiling (towed cable) data acquisition, the electrodes were dragged through the water by the use of a water-borne vessel. Eleven water-proof electrodes were used to measure electrical resistivity (Figure 12). In this survey, different spacing of the electrodes were used: 10, 20,30, and 50 feet in two different weather sessions, summer and winter.

Different software associated with each individual technology were used in data acquisition and the generation of $2 \mathrm{D}$ and $3 \mathrm{D}$ maps, and by integrating the interpretations of data from geophysical tools and ground truth (surface samples), detailed maps of bottom sediment and substrate were produced. 


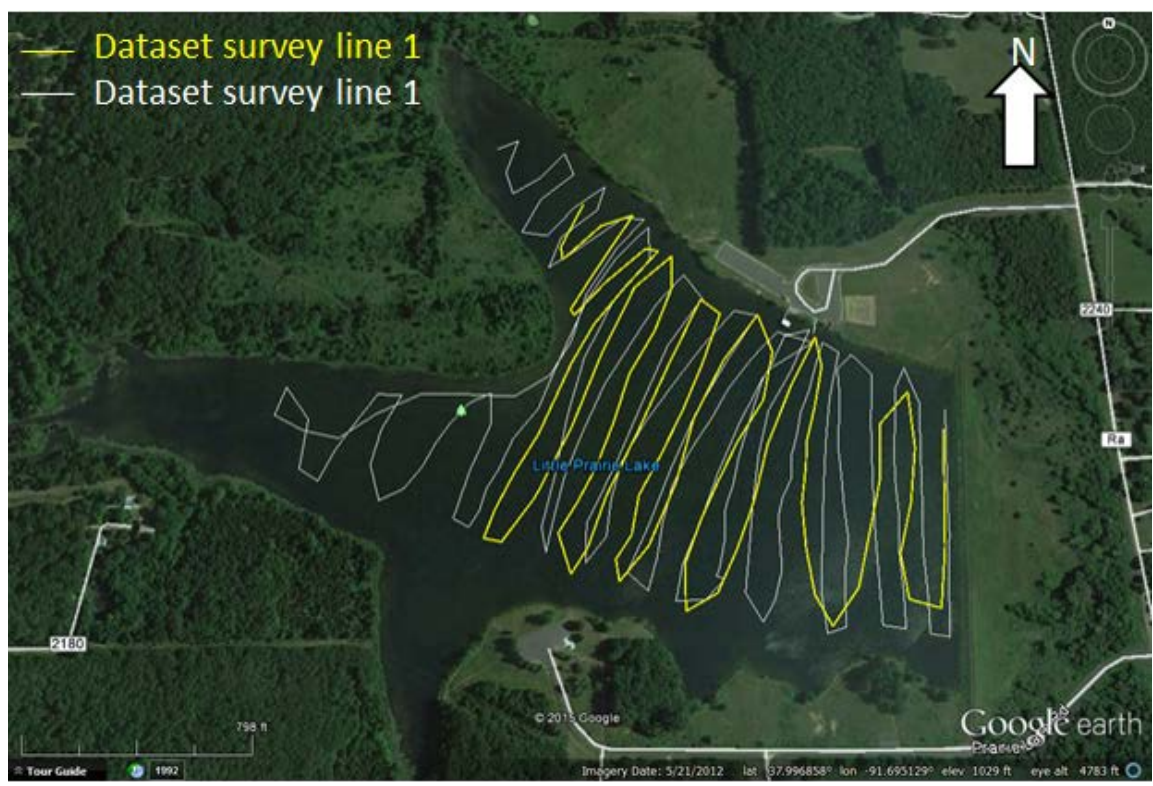

Figure 9. Side and down scan sonar data acquisition survey lines.

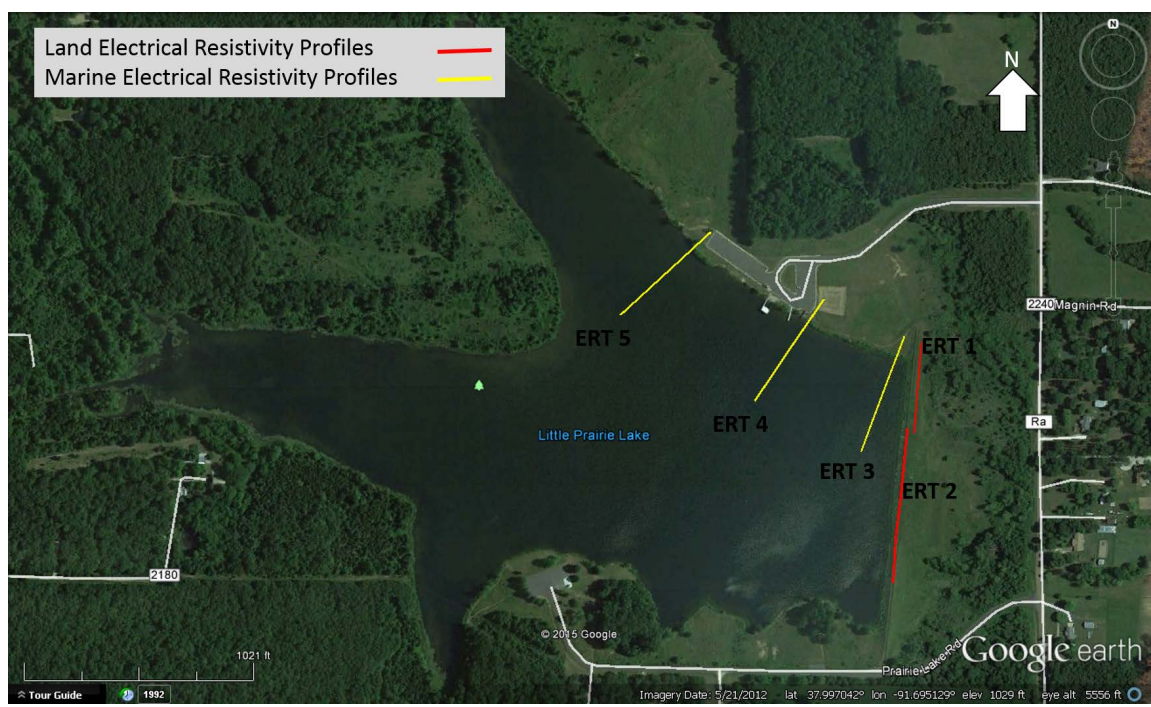

Figure 10. The location of the electrical resistivity tomography profiles on land (ERT1 and ERT 2), underwater electrical resistivity (ERT3, ERT4, ERT5).

\section{Geophysical Data Processing}

The DELPH 3.0 software coupled with Road Map software were utilized in data processing to offer a wide range of acoustic interpretation options for sonar and seismic data. The software is simple, easy to use, capable of interpreting complex data, and has batch reporting capabilities that help ensure the reliability of data acquisition in the field [30].

Sonar data processing helps generate a more accurate picture of the seabed compared to raw data displayed by a viewfinder, since the processing leads to the conversion and interpretation of data to greater depth.

The steps followed by DELPH 3.0 software in generating seabed maps include: 


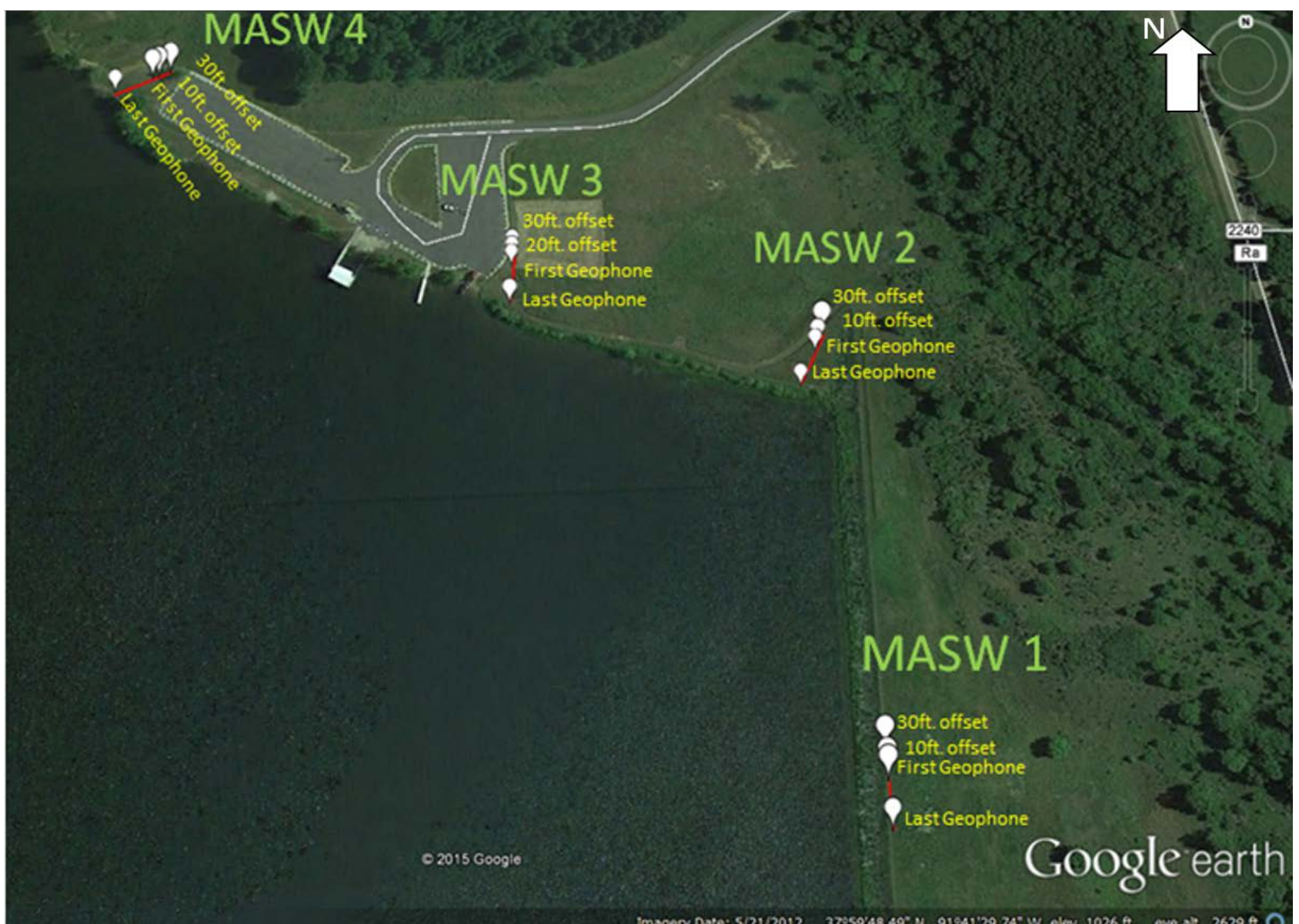

Figure 11. MASW profile locations for geophone spacing $2.5 \mathrm{ft}$. with different offsets.
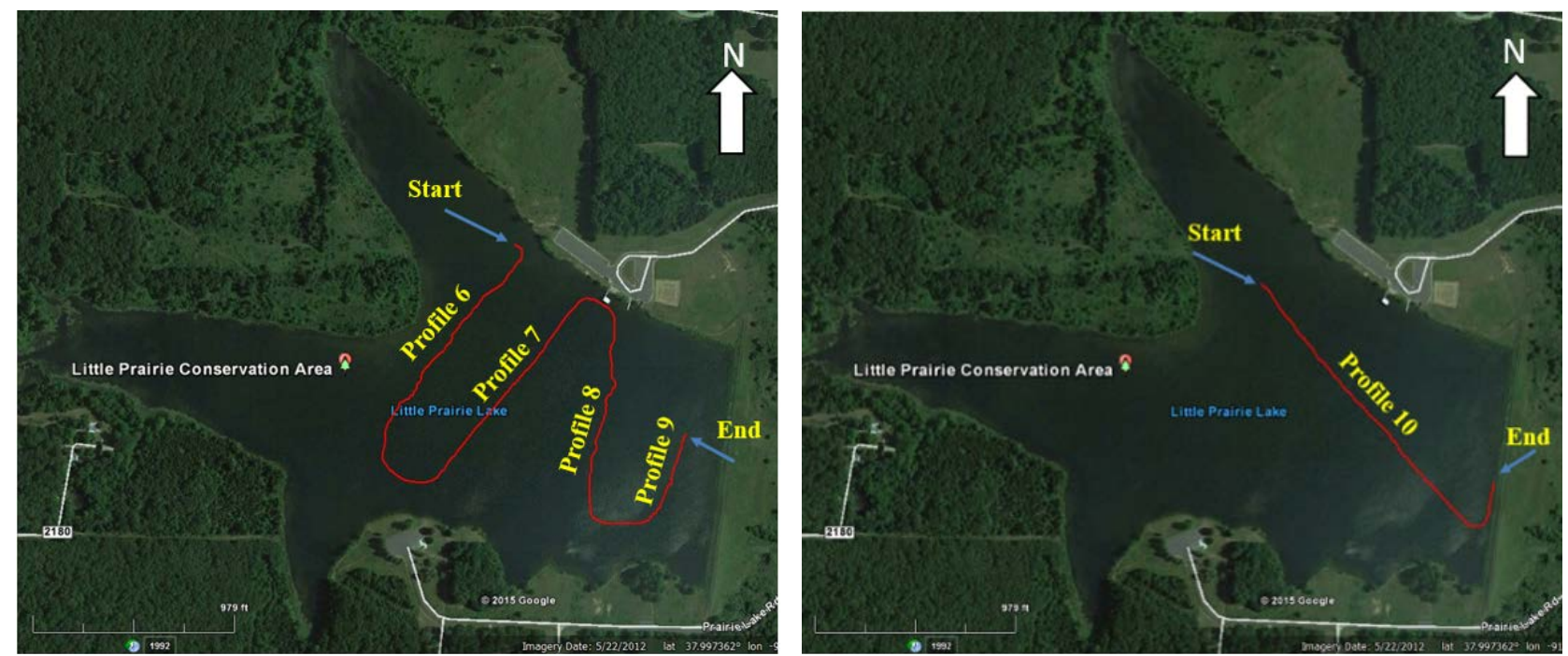

Figure 12. Survey lines location for 10 feet spacing of towed cable.

1) data organization in folders to allow for easy access and manipulation, and 2) file synchronization of software, such as Contact Manager and Delph Road Map, using the Delph Database Selector. Side scan sonar recodes geophysical data in 
an XTF format. This format allows for three channels of data to be recorded and analyzed: side scan sonar, down scan sonar, and starboard readings. The three data channels must be filtered in order to best analyze them (Figure 13).

The side scan image is based on an 8 bit $(0$ - 255) grey scale that represents the strength of returning signal to determine the type and texture of bottom sediments, according to the key below:

\begin{tabular}{|c|}
\hline Key to Side-scan Sonar Image Shading \\
CONVENTIONAL SCALE \\
Sonar shadow ----------Weak Signal Return ------------------Strong Signal Return \\
\hline
\end{tabular}

Weak signal returns, represented by the light gray color of the key, indicate smooth seabed sediments, coarse material, and subtle microtopography, while cobbles and gravels reflect greater amounts of strong incoming signal, and appears in a dark gray to black color in the right side of the scale.

Larger objects often create a sonar shadow, which could be calculated and used to determine the geometry of objects.

The electrical resistivity instrument records the data in Sting format (.stg), which is exported to the .dat format after being checked in the field for quality and for removal of bad data. Cleaned data is then plotted into 2D pseudo-sections to create a $2 \mathrm{D}$ inversion mathematical representation of the subsurface (model) using RES2DINV software.

\section{Results}

\subsection{Bathymetry Map}

Echo sounder and sub-bottom profiling were used to obtain water depth. Both tools indicate maximum water depths of $\sim 34$ feet, as illustrated in (Figure 14).

Determining the water depth was necessary in order to map old stream channels. The results reveal two old stream channels, in the western and northwestern

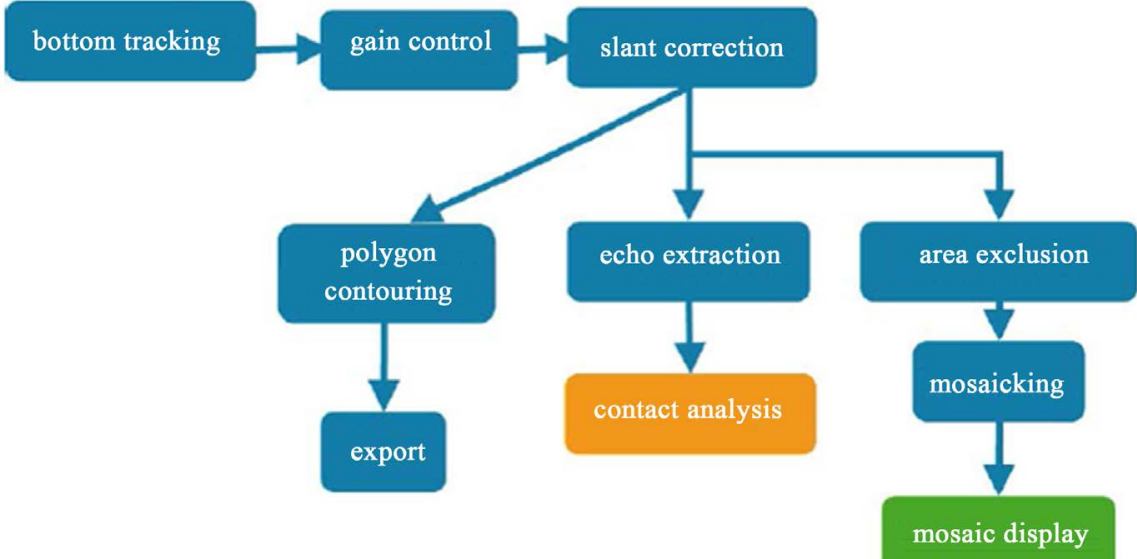

Figure 13. Processing steps chart for side scan sonar [30]. 


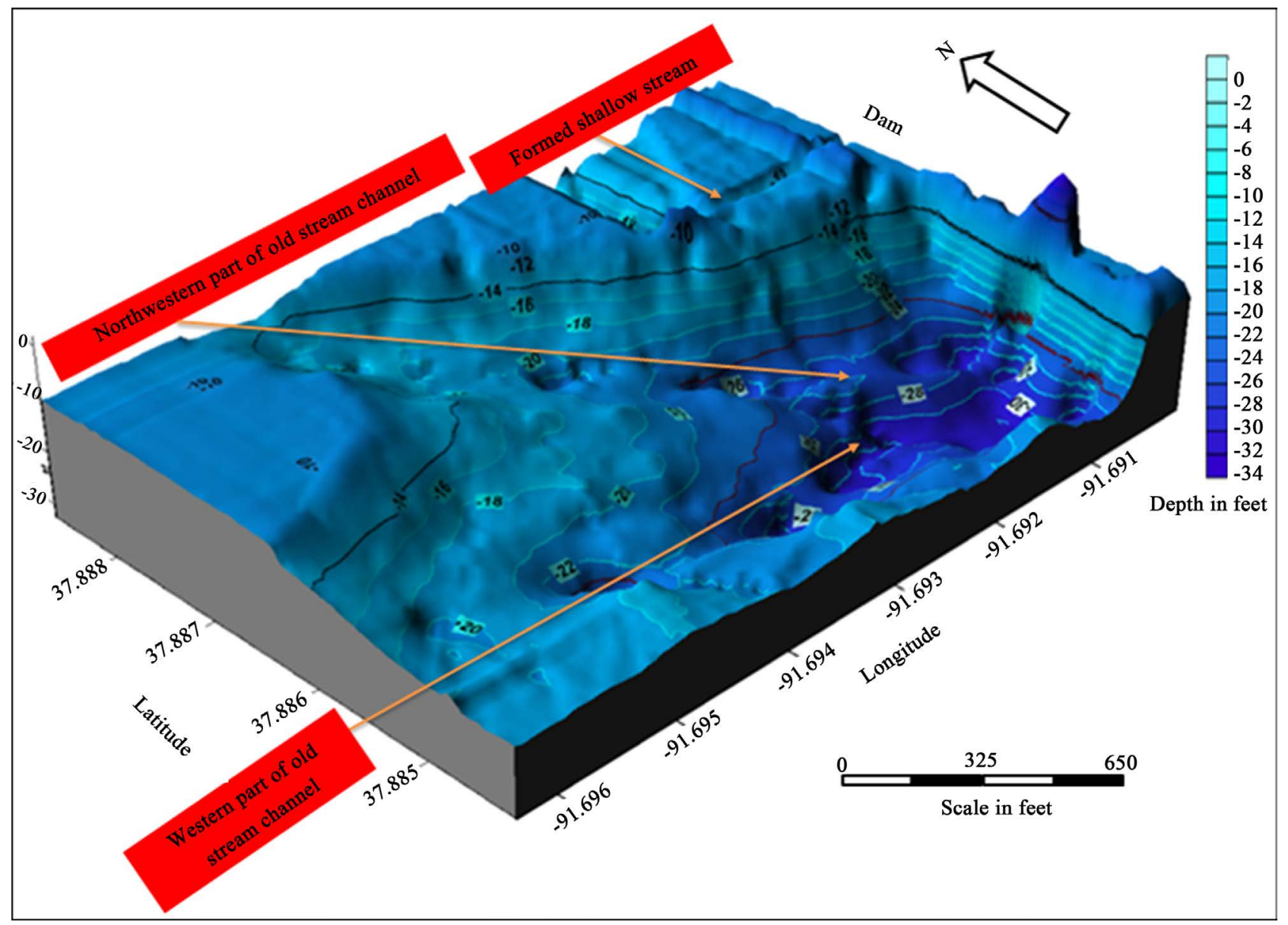

Figure 14. Water depth map produced from down scan sonar data.

sections of the study area respectively, united at maximum depth near the dam. The lower frequency of sub-bottom profiling result shows the paleosmall shallow stream channel that is covered by thick vegetation.

\subsection{Topography}

The topographic map of the lakebed determined from the colored contour map was obtained by filtered down scan sonar data. The map shows variations of lakebed topography and the direction of two old stream channels. It also shows the shallowest part of the lakebed (orange color) and the deepest parts of the lakebed (pink color), as displayed by Figure 15.

\subsection{Tree Hazard Mapping}

The result of mapping standing submerged trees and brush piles of the Lake were mapped using the side scan sonar technique (Figure 16). The yellow symbols represent the location of captured trees. The distribution pattern indicates that these trees primarily occupy old stream channels. As a result, side scan sonar is an applicable method for mapping hazardous objects on the lakebed. Submerged trees were not removed before the dam construction, and this may 


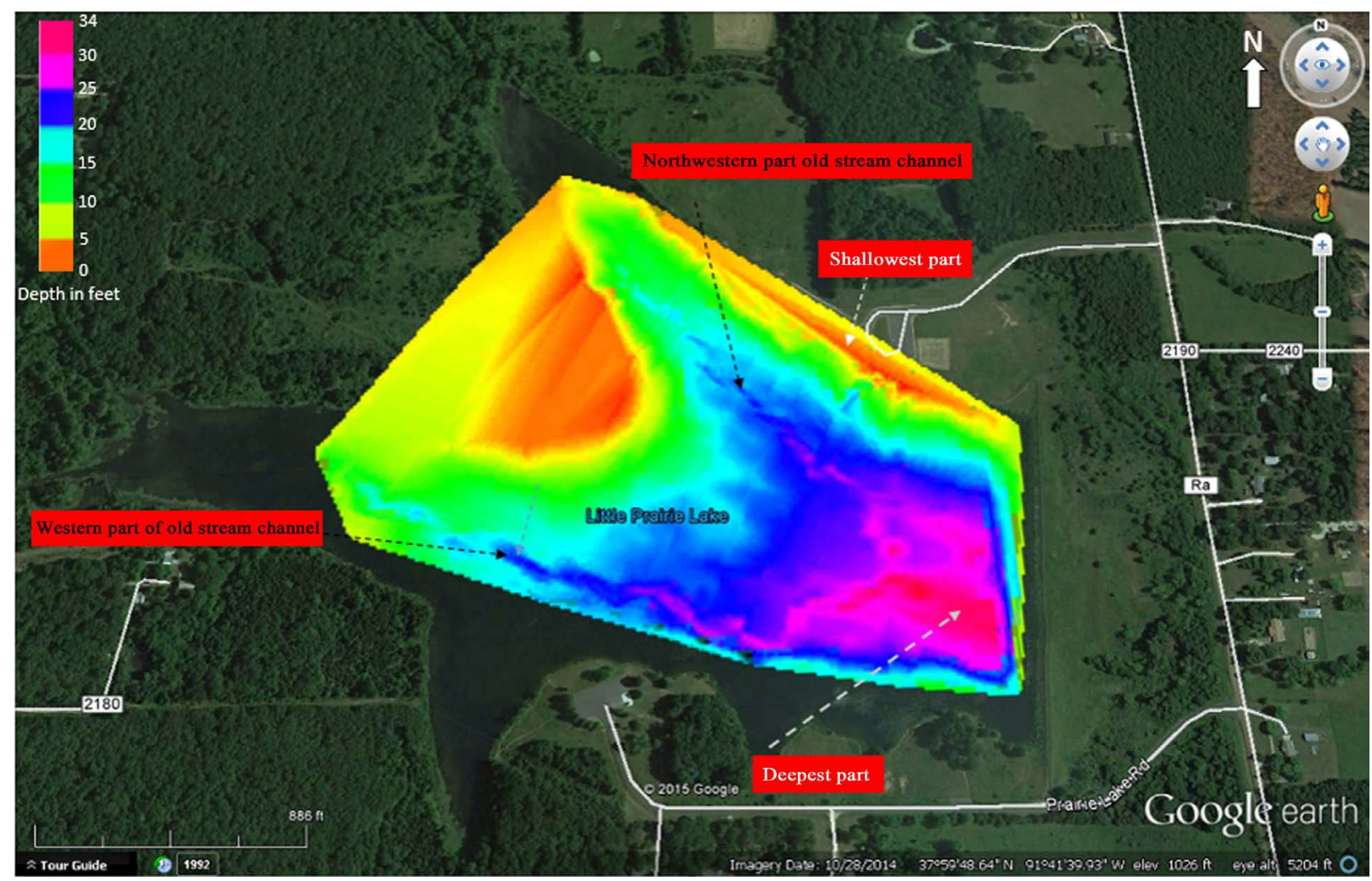

Figure 15. Colored contour map of the lake exported to Google Earth.

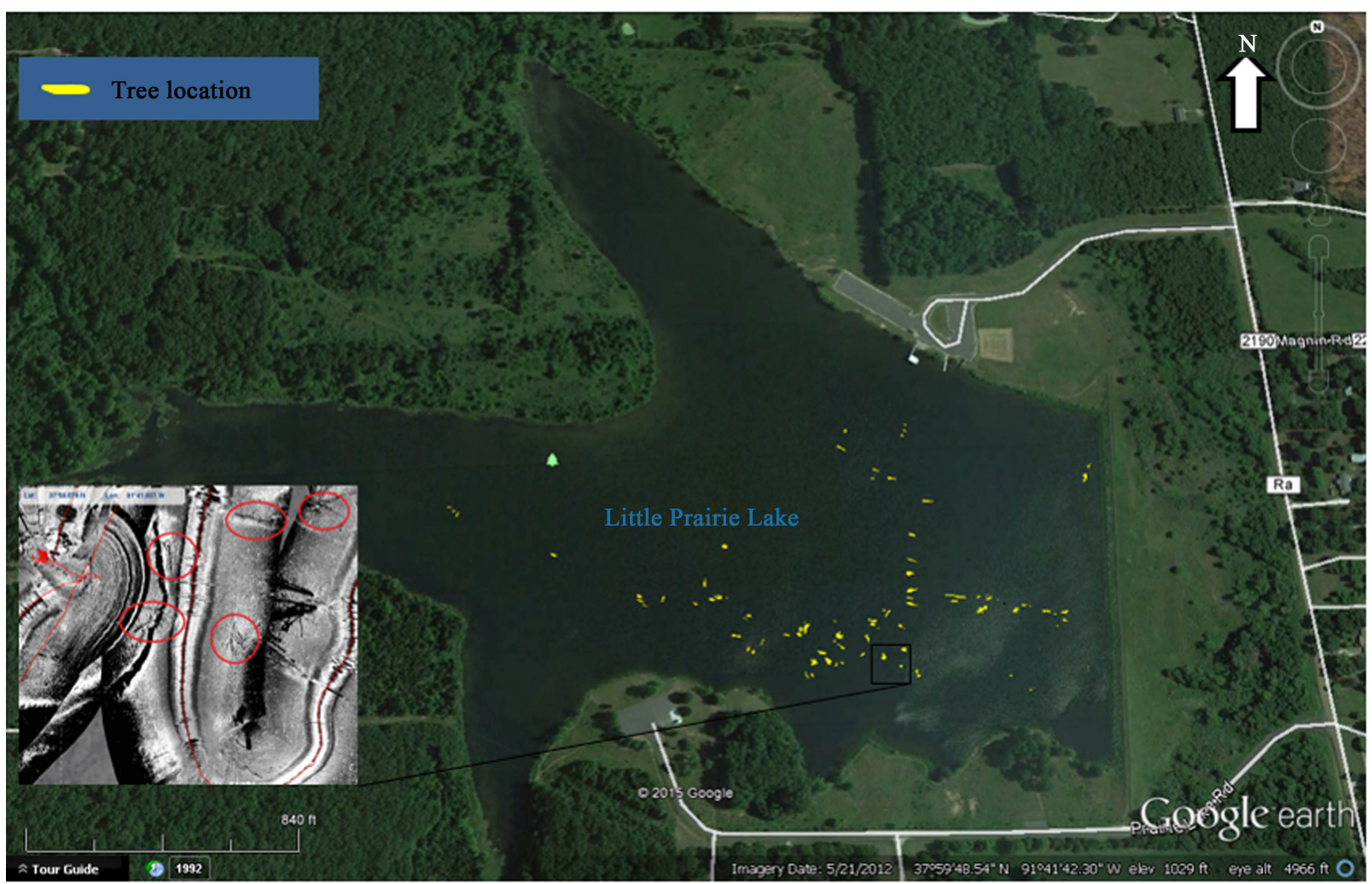

Figure 16. Location of submerged trees and brush piles shown in yellow symbols. 
have been done to enhance ecosystem life. However, it is still important to determine the location of hazardous objects such as trees for safety purposes in order to prevent fatal accidents.

\subsection{Benthic Habitat Map}

The habitat map was produced from side scan sonar data by analyzing the differences in texture. The map in Figure 17, illustrates the variation between grass, soil, boulders, and stream boundaries.

Milfoil weed, represented by the dark-green color on the map, is shown to encircle the lake. This result is similar to the milfoil map obtained from MCD, which shows that milfoil weed is concentrated primarily close to shorelines. Milfoil weed has numerous advantages, including, 1) stabilizing sediment, 2) reducing the erosion of the lakebed, and 3) protecting fish and wildlife habitats.

Soil deposits are indicated by the green-sea color. The stream boundaries were determined by the dark blue colors on the image. Interpreted boulders are represented by the white color.

Few inches of sediment samples were collected from the lakebed surface and their locations are presented in Figure 18 and Table 1. The samples could be consisting of silty loam and silty clay. No deep boreholes are available to compare them with the geophysical results.

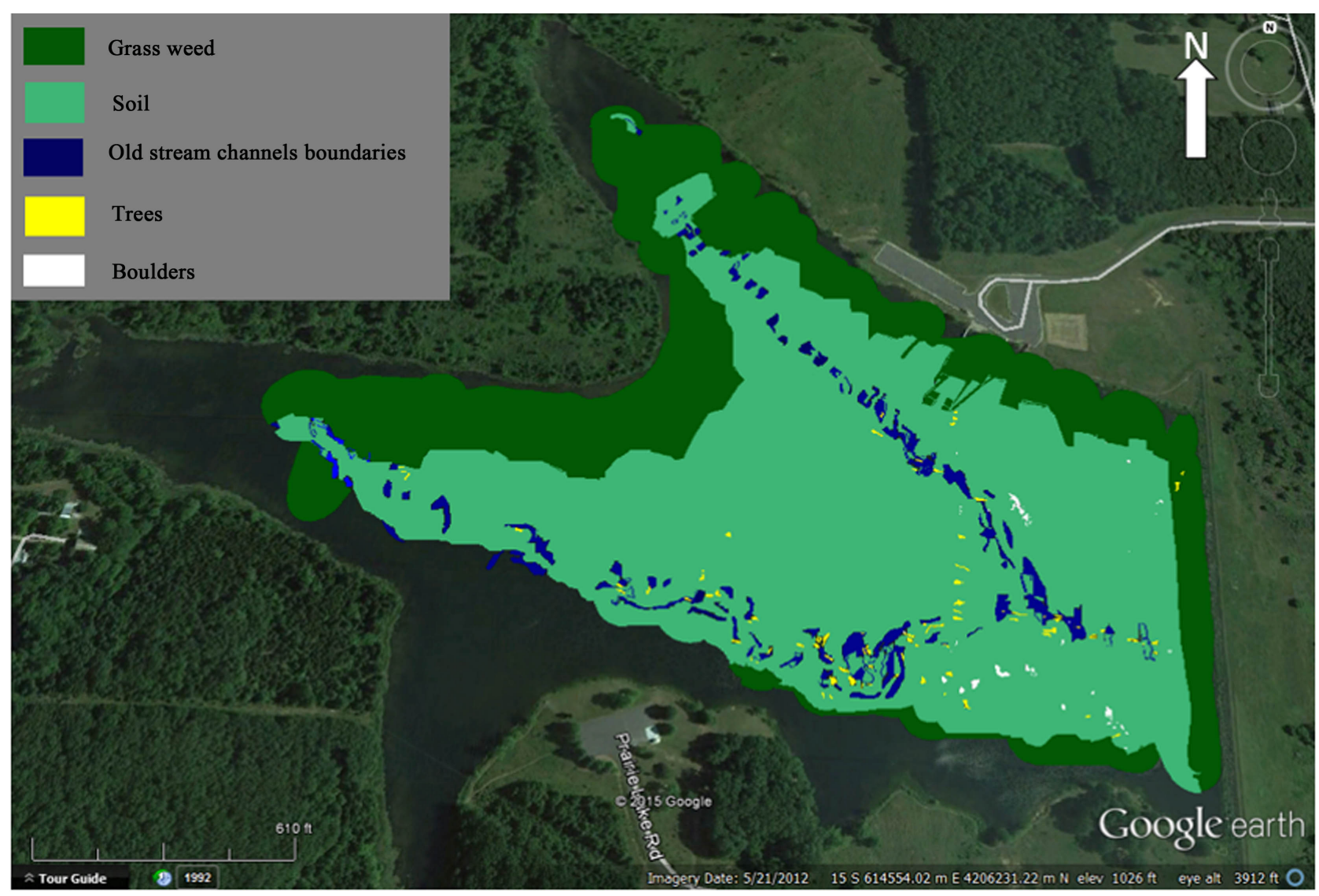

Figure 17. Habitat map of little prairie lake. 


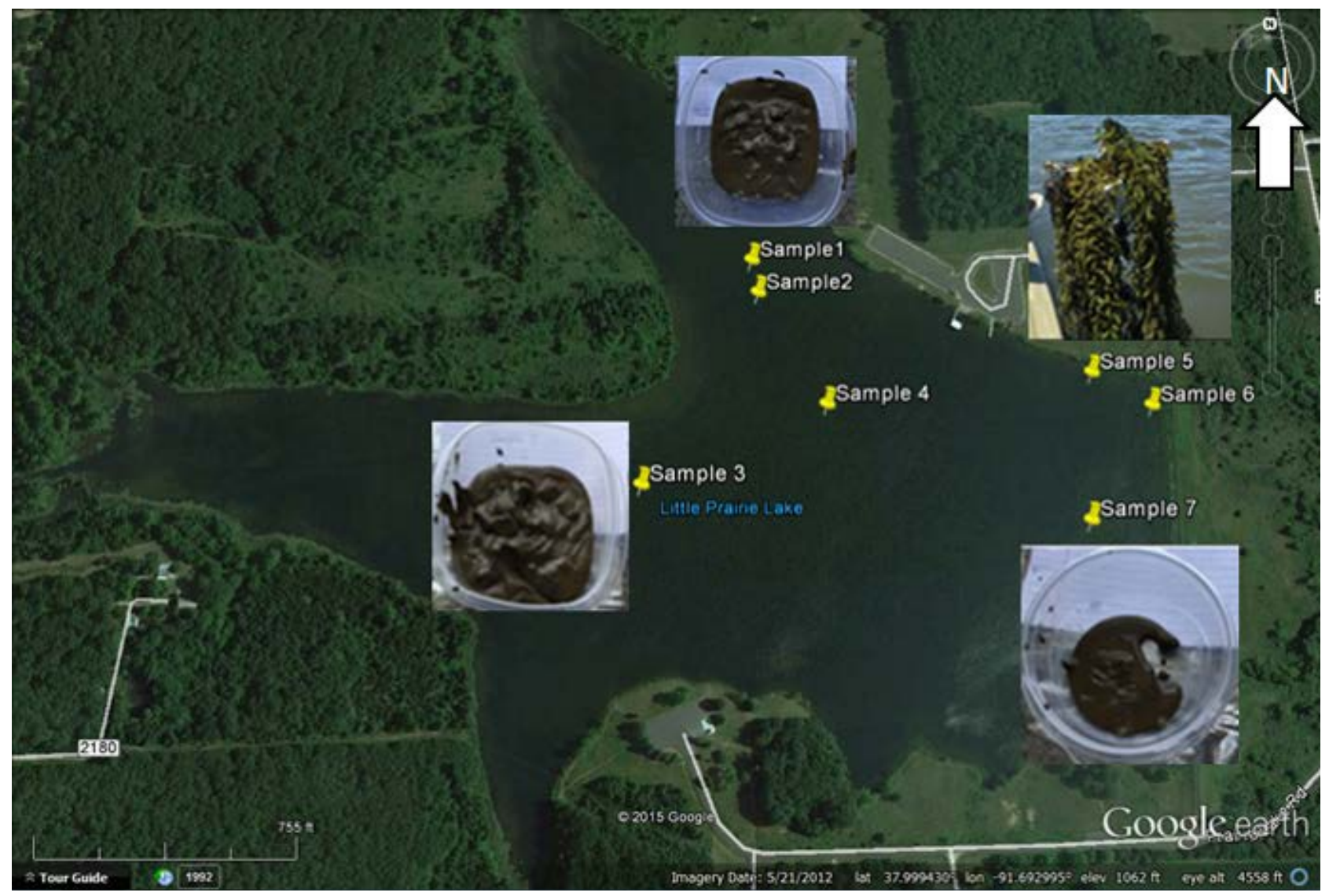

Figure 18. Soil sample locations.

Table 1. Shows the description of samples collected from the lake bottom.

\begin{tabular}{cc}
\hline Sample No. & Sediments characterization \\
\hline Sample 1 & Soil (Silty loam) \\
Sample 2 & Soil (Silty clay) \\
Sample 3 & Soil (Silty clay) \\
Sample 4 & Soil (Silty clay) \\
Sample 5 & Milfoil weed \\
Sample 6 & Soil (Silty clay) \\
Sample 7 & Soil (Silty clay) \\
\hline
\end{tabular}

\subsection{Results of Sediments and Bedrock}

The interpretation of electrical resistivity tomography profiling and continuous resistivity profiling data were used to determine the electrical resistivity values of soil and rock. Data showed soil with high conductivity, which could indicate silty/clay and/or clayey soil, having a low electrical resistivity value of $<\sim 30$ ohm-meter, followed by soil with low conductivity, which could indicate silty/loam and/or loamy soil, with an electrical resistivity value between $\sim 30-105$ ohm-meter. The data also showed weathered rock with an electrical resistivity between $105-400 \mathrm{ohm}$-meter, and intact rock with electrical resistivity value > $400 \mathrm{ohm}$-meter, as well as the presence of NW-SE and SW-NE jointing (Figure 19). 

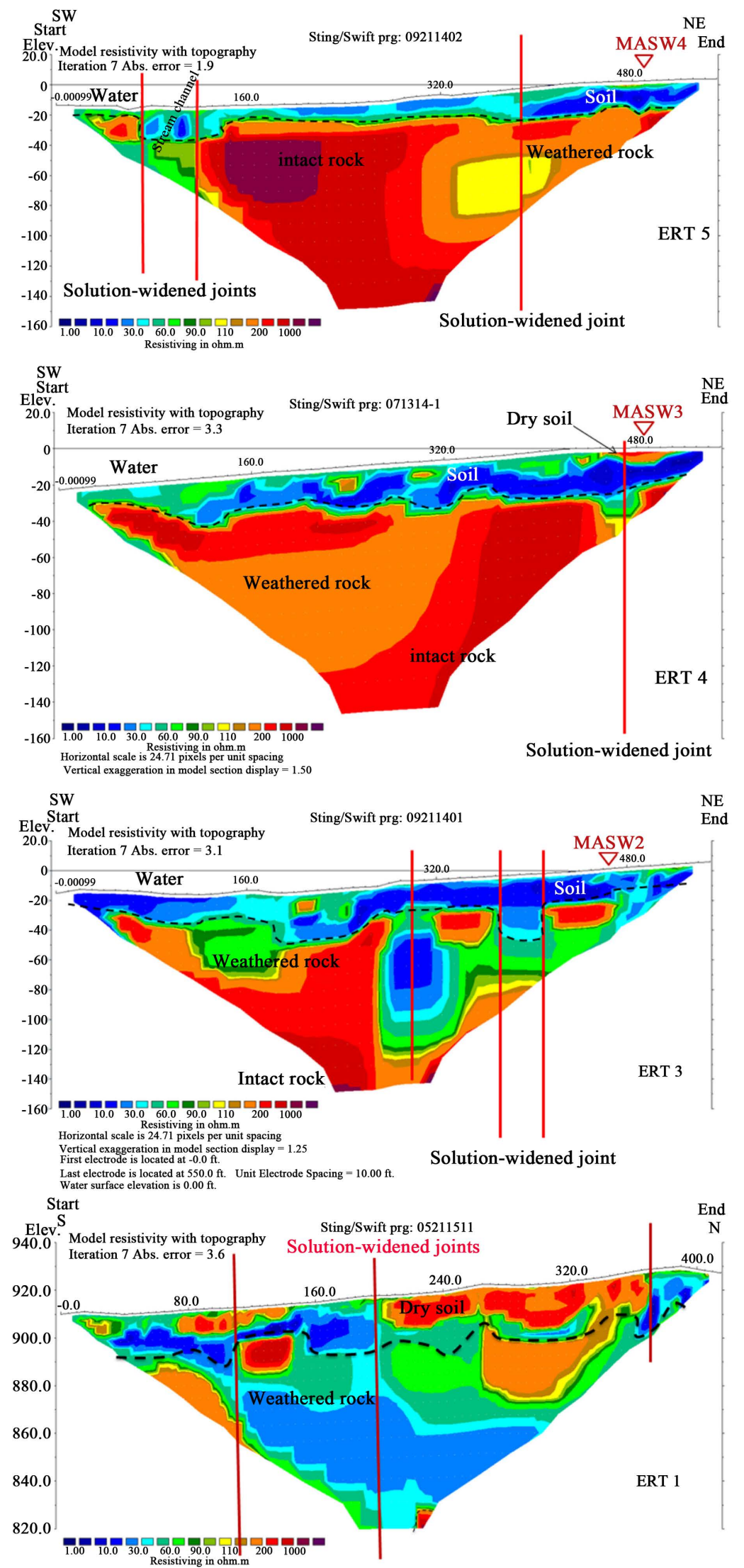

Figure 19. ERT profiles 1, 3, 4, and 5 showing the solution-widened joints. 
The interpretation of multi-channel analysis of surface wave data shows soil, weathered rock, and intact rock with shear wave velocity values of between $\sim 600$ - 1500, 1500 - 2200 and $>2200$ feet/sec respectively.

The interpretation of electrical resistivity tomography profiling, continuous resistivity profiling, and multi-channel analysis of surface wave data show that the depth of rock of the lake and on land generally varies between $\sim 7$ and 48 feet, increasing towards the eastern direction of the lake.

The on-land ERT 2 Profile result was acquired over the dam of the 2D geoelectrical section displays intact rock at a constant average depth of $\sim 45$ feet, with a high electrical resistivity value $>400 \mathrm{ohm}$-meter (Figure 20). The upper layer consists of dry soil of thickness $\sim 9$ feet, underlain by compacted clay $\sim 35$ feet thick, having a low electrical resistivity value of less than $30 \mathrm{ohm}-\mathrm{meter}$, followed by a thin layer of weathered rock of medium electrical resistivity value ranging between $\sim 60$ and $400 \mathrm{ohm}$-meter.

Results of one-D shear wave velocity model for profile MSAW1 (Figure 21), acquired on-land over the dam, and shows dry soil on the upper layer, underlain by compacted clay layer, weathered rock, and intact rock. The thicknesses of the aforementioned layers were $\sim 9,36,12$ and $>57$ feet, respectively.

The CRP profiles (Figure 22), along the northwestern old stream channel, showed that sediments consist of soil with high conductivity, having an electrical resistivity value between $\sim 30$ and 105 ohm-meter, underlain by weathered rock of electrical resistivity value between $\sim 105$ and 400 ohm-meter, and several solution widened joints trending SW/NE. The CPR profiles that were acquired in the deepest central part of the lake are composed of soil with high conductivity, having electrical resistivity value between $\sim 30$ and $105 \mathrm{ohm}$-meter (Figure 23). Soil with a higher conductivity was determined by the CPR profiles, having the electrical resistivity profiles. Soil with high conductivity was overlain by soil with low conductivity close to shorelines. These results indicate the existence of soil

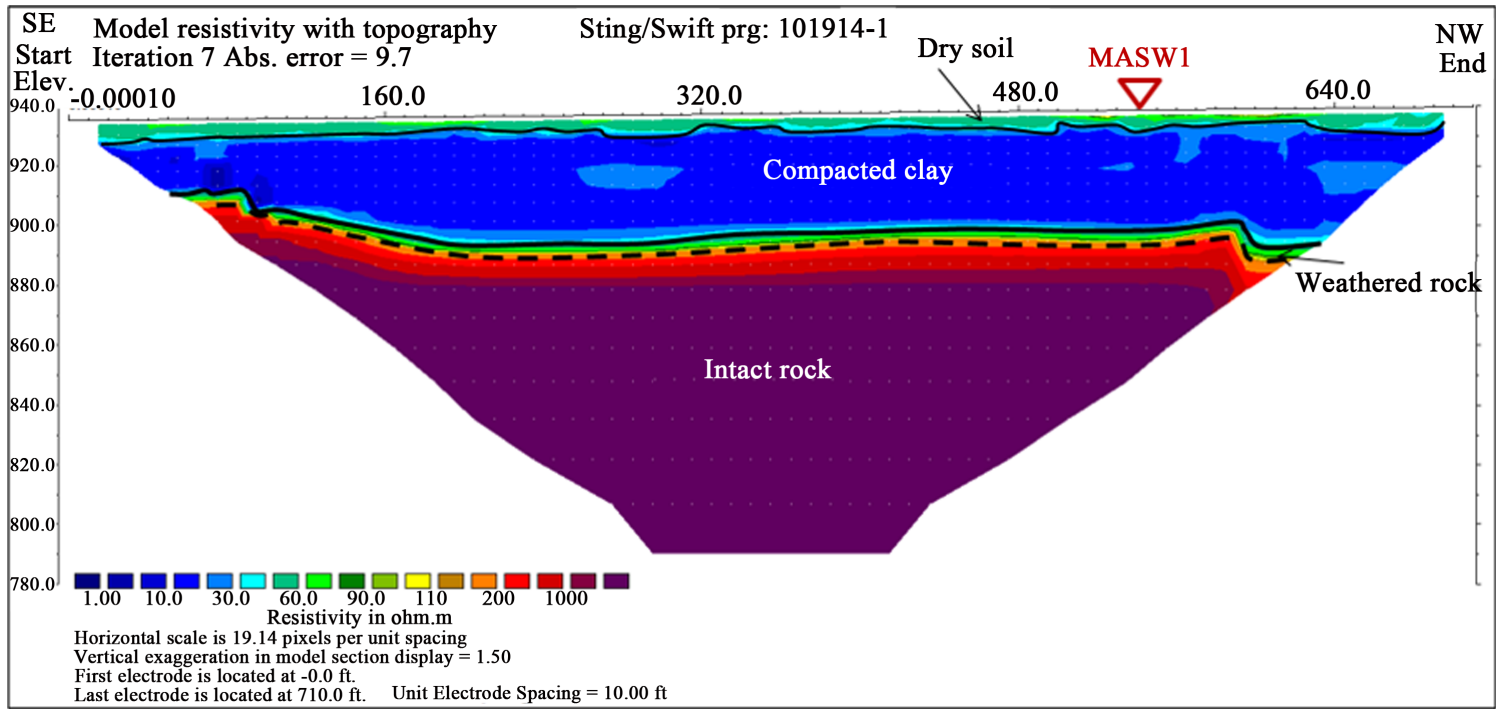

Figure 20. The 2D geoelectrical section of on-land ERT 2 Profile. 


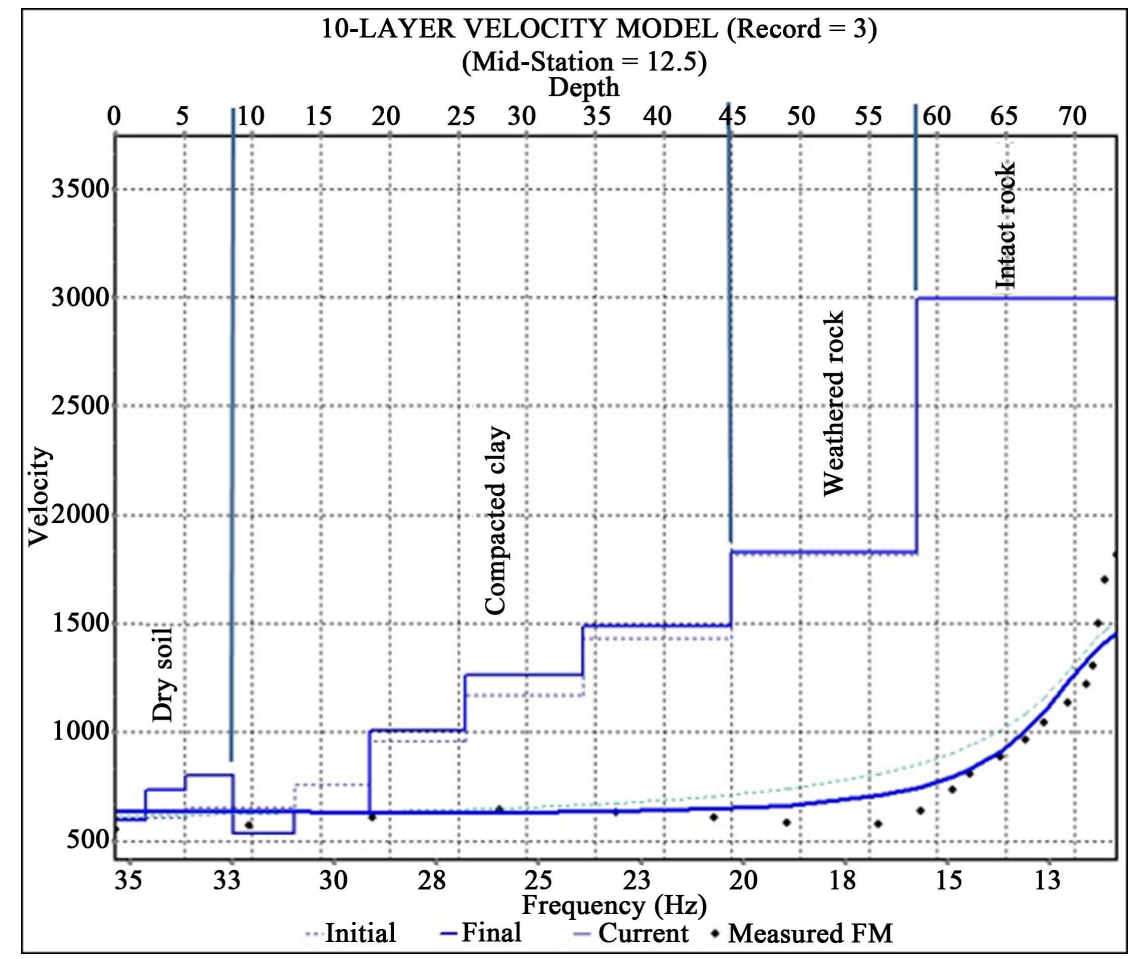

Figure 21. 1D shear velocity model of MASW1.

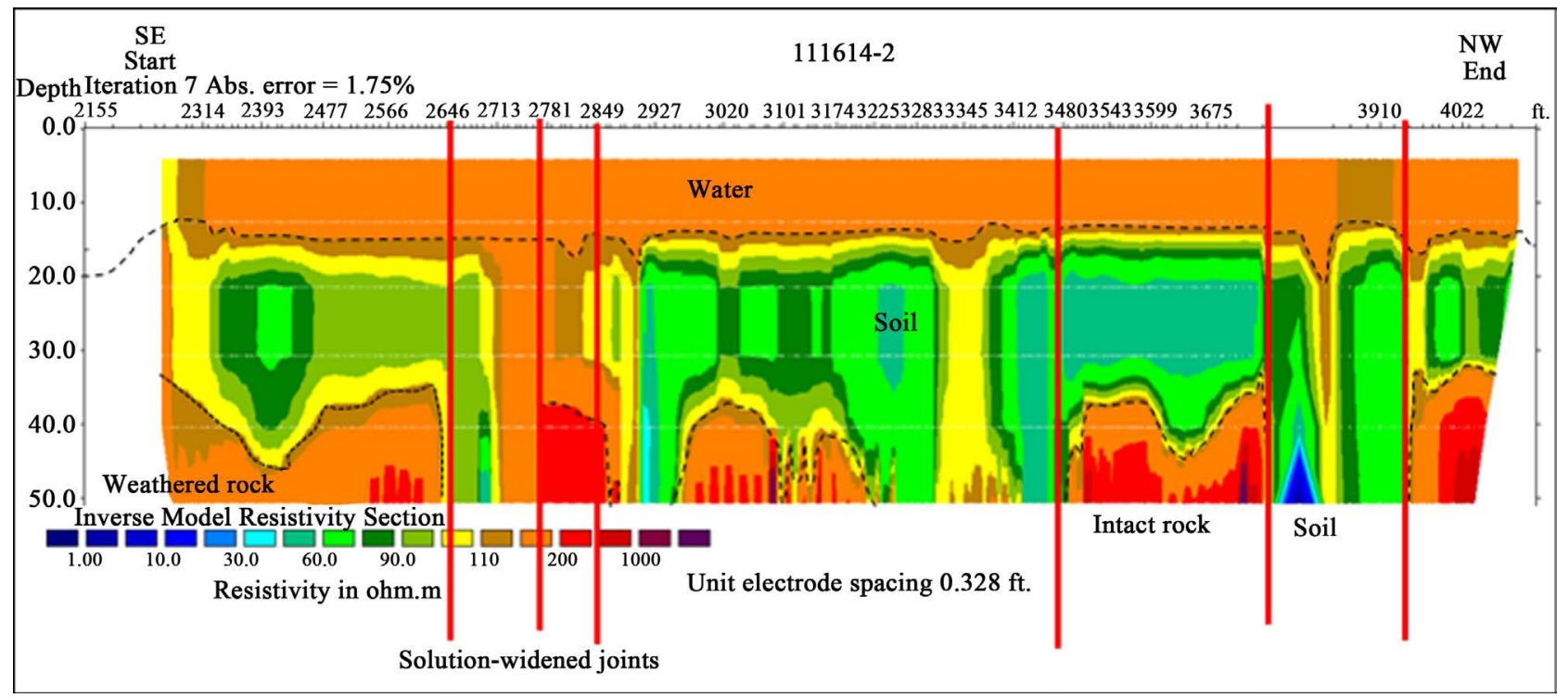

Figure 22. Profile 13 of 2D geoelectrical CRP at 20 feet electrode spacing along the northwestern old stream channel.

with high conductivity is increasing towards shorelines and disappear in locations of old stream channels and the central deepest part of the lake (Figures 24-26).

Results from CRP, electrical resistivity tomography, and benthic habitat map confirmed the geological information of the lake indicating that the flood plain consists of silty loam, and that the slope consists of silty loam underlain by silty clay [19]. 


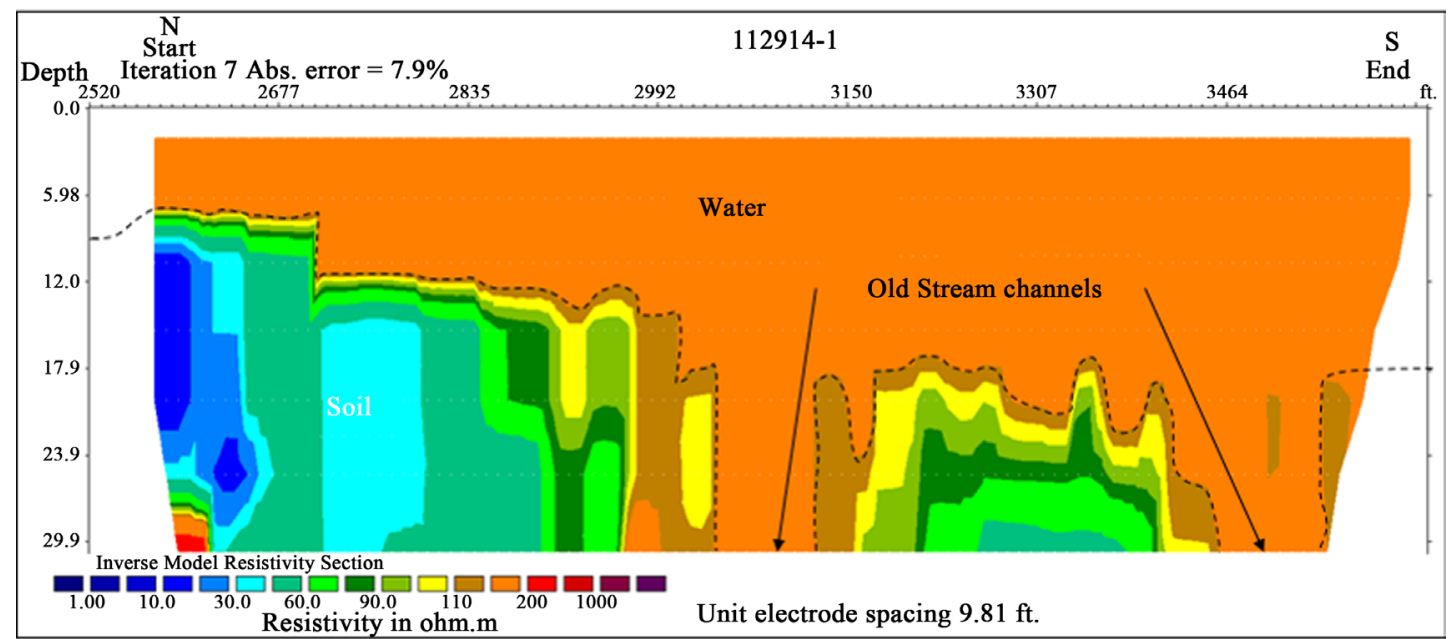

Figure 23. Profile 8 of 2D geoelectrical CRP at 10 feet electrode spacing at the central part of the lake.

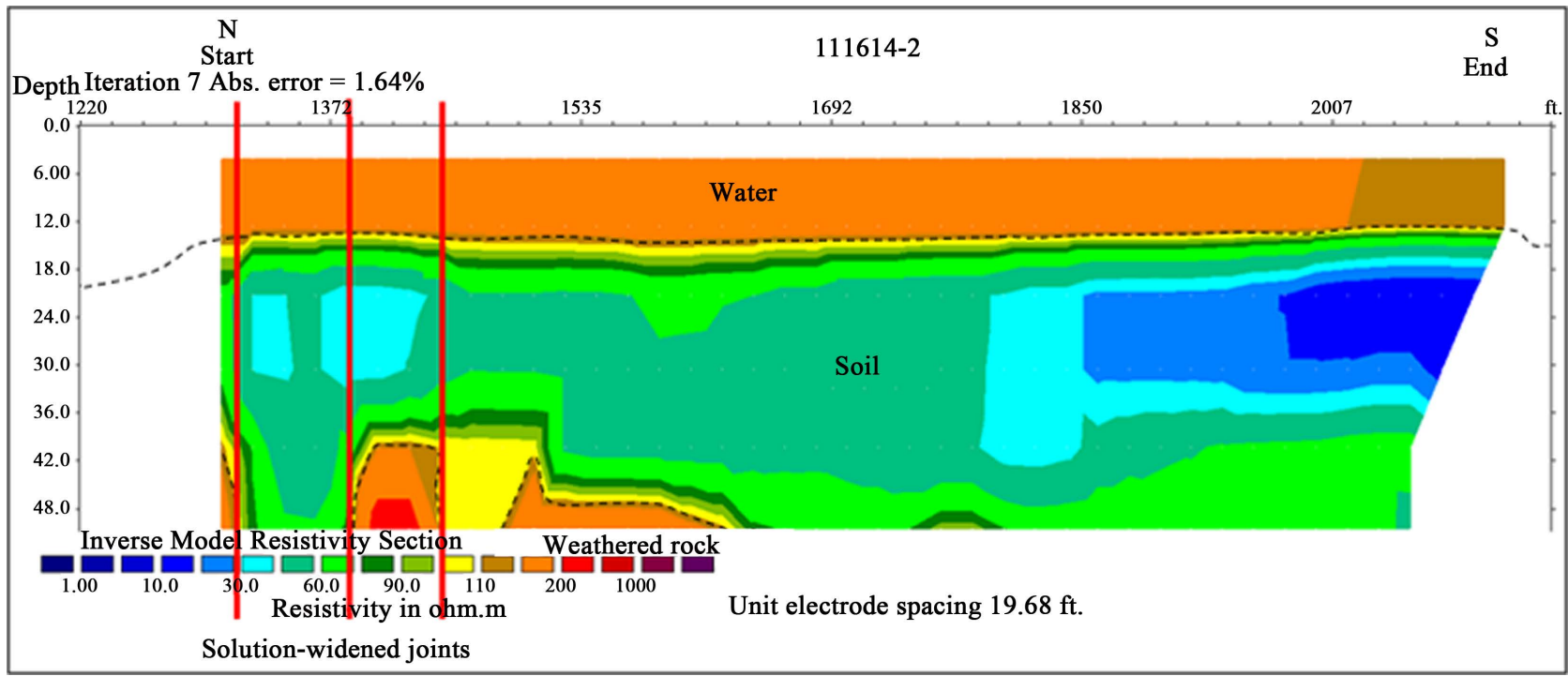

Figure 24. Profile 12 location of CRP at 20 feet electrode spacing $\sim 20 \mathrm{~m}$ from the dam.

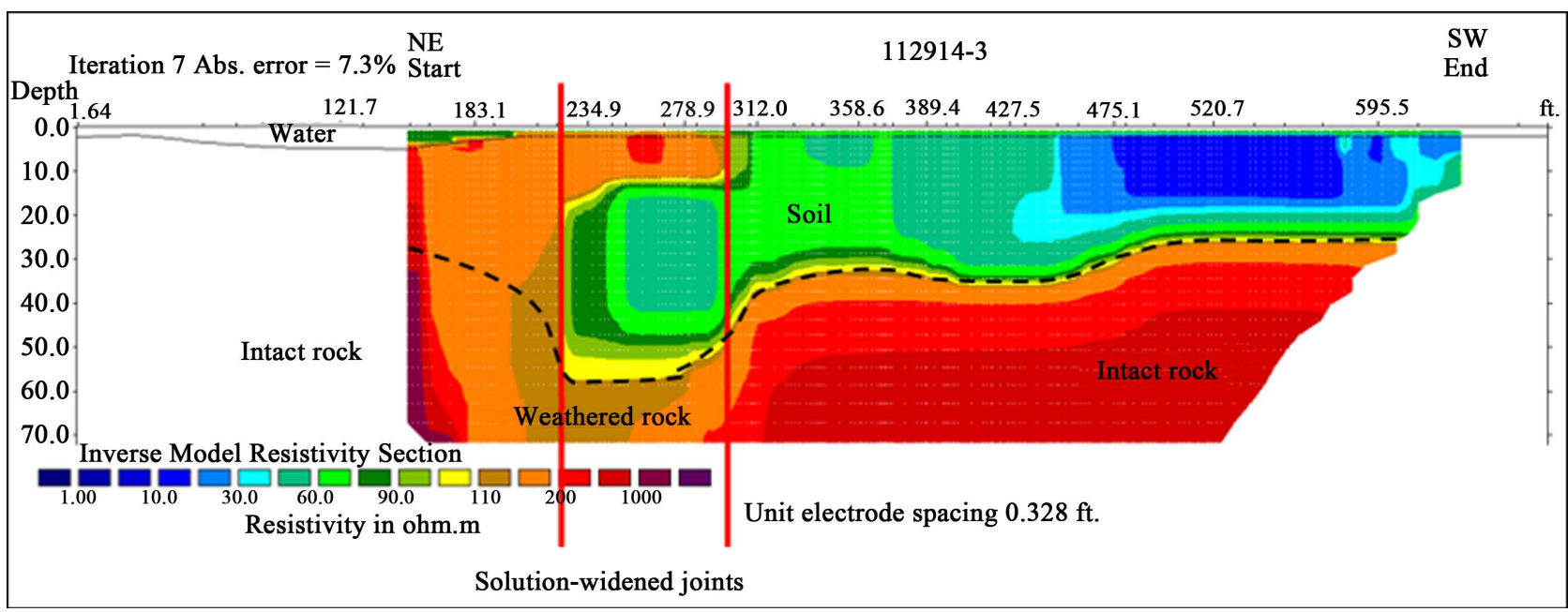

Figure 25. Profile 16 of 2D geoelectrical CRP at 30 feet electrode spacing near the north west shoreline. 


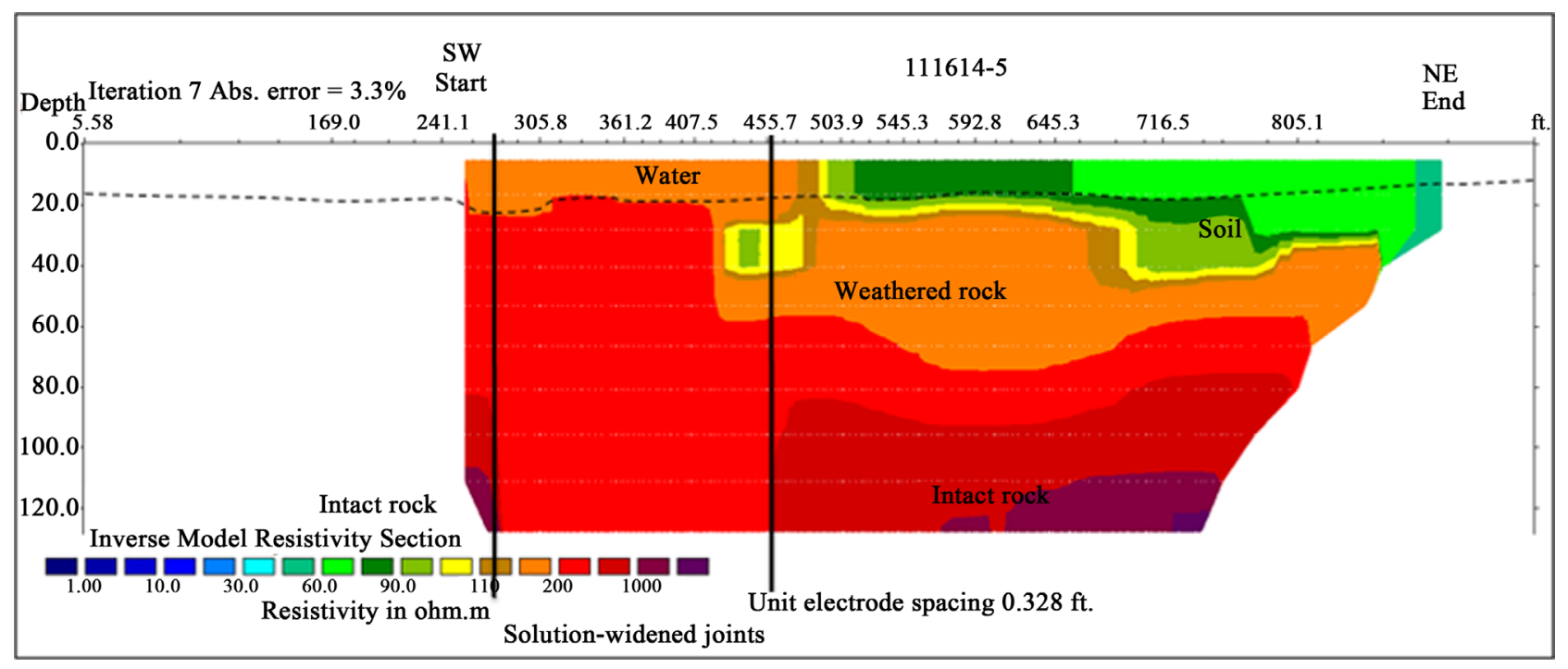

Figure 26. Profile 17 of 2D geoelectrical CRP section at 50 feet electrode spacing near north eastern shoreline.

\section{Conclusion}

The aim of the study was to provide researchers, the community, and authorities with baseline information on the conditions of the bottom of Little Prairie Lake, in order to assist in future developments as well as to investigate the utilization of integrated, distinctive land and marine geophysical tools. Results of ERT and CRP profiles showed NW-SE and SW-NE trending joints along the old streams channels, and also close to the northern shoreline. Bedrock was dissolute and weathered. The result of CPR and ERT profiles proved the ability to determine the top of rock and showed that the average depth to top of the rock varies between 7 and 48 feet. ERT and MASW were used to determine the depth of sediments and rock on land. Both methods show three main layers soil, weathered rock, and intact rock. A discrepancy of $\sim 3.0$ feet in the reported depth between ERT and MASW is due to the high sensitivity of ERT to minor changes in lithology and topography of target layers, unlike MASW, which require flat layers to detect exact depth of the layer. Lake sediments are characterized by low conductive silty/loam and/or loamy soil (ER value between $\sim 30$ and 105 ohm-meter), along the old stream channel, and at the deepest part at the Lake center; underlined by weathered rock. Higher conductive silty clay and/or clayey soil (ER value $<\sim 30 \mathrm{ohm}$-meter) was reported, with an increasing trend towards shorelines. ERT1 and MASW1 profiles were acquired over the crest of the dam for inspection purposes. The results were interpreted to be dry soil, compact clay, weathered rock, and intact rock with a thickness of $\sim 9,36,12$, and $>57$ feet, respectively, and that the rock was approximately consistent, intact and free of joints and fractures. Side scan sonar is capable of mapping and generating benthic habitat maps, based on the variation of texture and mapping hazardous objects of lakebeds for safety purposes. The bathymetry maps produced from sub-bottom profiling and down scan sonar data, showed a maximum water depth of $\sim 34$ feet and determined the location and direction of the two old stream channels that 
are directed from NW and W-E. The depth result could be used as a base-line and future reference for monitoring changes in lake sediments.

\section{Acknowledgements}

We would thank the Geosciences, Geological, and Petroleum Engineering Department at Missouri University of Science and Technology for providing the assistance. I would also thank my colleague Abdullah Dera for providing help in the project.

\section{Conflicts of Interest}

The authors declare no conflicts of interest regarding the publication of this paper.

\section{References}

[1] Elliott, W.R. (2010) Below Missouri Karst. Missouri Department of Conservation. http://mdc.mo.gov/conmag/2000/03/below-missouri-karst

[2] Fluery, S. (2009) Land Use Policy and Practice on Karst Terrains: Living on Limestone. Springer, Berlin.

[3] Robertson, J. (2013) The Science of Sinkholes. United States Geological Survey. http://www.usgs.gov/blogs/features/usgs_top_story/the-science-of-sinkholes

[4] Williams, J.H. and Vineyard, J.D. (1976) Geologic Indicators of Subsidence and Collapse in Karst Terrain in Missouri. In: 55th Annual Meeting, Transportation Research Board, Washington DC, 31-37.

[5] Reger, J.P. (2012) Foundation Engineering Problems and Hazards in Karst Terrains. Maryland Geological Survey, Maryland Department of Natural Resources. http://www.mgs.md.gov/geology/geohazards/engineering_problems_in_karst.html

[6] Van Beynen, P. (2011) Karst Management. Springer, Berlin. https://doi.org/10.1007/978-94-007-1207-2

[7] Xeidakis, G.S., Torok, A., Skias, S. and Kleb, B. (2004) Engineering Geological Problems Associated with Karst Terrains: Their Investigation, Monitoring, and $\mathrm{Mi}$ tigation and Design of Engineering Structures on Karst Terrains. Bulletin of the Geological Society of Greece, 36, 1932-1942. https://doi.org/10.12681/bgsg.16679

[8] Palmer, Arthur, Palmer, Margaret and Sasowsky, I. (1999) Karst Modeling. Karst Waters Institute.

[9] Šumanovac, F. and Weisser, M. (2001) Evaluation of Resistivity and Seismic Methods for Hydrogeological Mapping in Karst Terrains. Journal of Applied Geophysics, 47, 13-28. https://doi.org/10.1016/S0926-9851(01)00044-1

[10] Nitsche, F.O., Bell, R., Carbotte, S.M., Ryan, W.B.F. and Flood, R. (2004) Process-Related Classification of Acoustic Data from the Hudson River Estuary. Marine Geology, 209, 131-145.

[11] Rollet, N., Logan, G.A., Ryan, G., Judd, A.G., Totterdell, J.M., Glenn, K., Jones, A.T., Kroh, F., Struckmeyer, H.I.M., Kennard, J.M. and Earl, K.L. (2009) Shallow Gas and Fluid Migration in the Northern Arafura Sea (Offshore Northern Australia). Marine and Petroleum Geology, 26, 129-147. https://doi.org/10.1016/j.marpetgeo.2007.07.010

[12] Passaro, S. (2010) Marine Electrical Resistivity Tomography for Shipwreck Detec- 
tion in Very Shallow Water: A Case Study from Agropoli (Salerno, Southern Italy). Journal of Archaeological Science, 37, 1989-1998. https://doi.org/10.1016/j.jas.2010.03.004

[13] Missiaen, T., Slob, E. and Donselaar, M.E. (2008) Comparing Different Shallow Geophysical Methods in a Tidal Estuary, Verdronken Land van Saeftinge, Western Scheldt, the Netherlands. Geologie En Mijnbouw. Tijdschrift Van Het Nederlandsch Geologisch-Mijnbouwkundig Genootschap, 87, 151.

[14] Dai, Y.C. (2013) Integrated Application of Marine Geophysical Technology in a Seawall Reinforcement Project. Advanced Materials Research, 1636-1642.

[15] Negri, S., Margiotta, S., Quarta, T., Castiello, G., Fedi, M. and Florio, G. (2015) Integrated Analysis of Geological and Geophysical Data for the Detection of Man-Made Underground Caves in an Area in Southern Italy. Journal of Cave and Karst Studies, 77, 52-62.

[16] Welc, F., Mieszkowski, R., Vrkljan, G.L. and Konestra, A. (2017) An Attempt to Integration of Different Geophysical Methods (Magnetic, GPR and ERT); A Case Study from the Late Roman Settlement on the Island of Rab in Croatia. Studia Quaternaria, 34, 47-59.

[17] Missouri Department of Conservation, Rolla, Missouri.

[18] Barks, J.H. (1976) Water-Quality Characteristics of Six Small Lakes in Missouri. Rolla, Missouri Division of Geology and Land Survey Water Resources Report 33, $20 \mathrm{p}$.

[19] Missouri Department of Natural Resources, GeoSTRAT Program. http://dnr.mo.gov/geology/geostrat.htm

[20] United States Department of Agriculture (2002) Soil Survey of Phelps County, Missouri.

http://www.nrcs.usda.gov/Internet/FSE_MANUSCRIPTS/missouri/MO161/0/Phelp s_MO.pdf

[21] Heller, R.L. (1954) Stratigraphy and Paleontology of the Roubidoux Formation of Missouri. Volume 35 of Reports, Missouri. Division of Geological Survey and Water Resources.

[22] Savini, A. (2011) Side-Scan Sonar as a Tool for Seafloor Imagery: Examples from the Mediterranean Continental Margin. Sonar Systems. Ed. N.Z. Kolev. Intech. https://doi.org/10.5772/18375

[23] Vaduva, F. (2000) Sea Beam Multi Beam Theory Operation. L-3 Communications.

[24] Thorpe, E. and Thorpe, S. (2011) The Pearson CSAT Manual 2011. Pearson Education India.

[25] Nueman, S. (2013) What's Lurking in Your Lake: Sonar Turns up Startling Finds. NPR. Web.

http://www.npr.org/blogs/thetwo-way/2013/09/26/226523055/police-getting-help-fr om-cheap-easy-to-use-side-scan-sonar

[26] Wightman, W.E., Jalinoos, F., Sirles, P. and Hanna, K. (2003) Application of Geophysical Methods to Highway Related Problems. Federal Highway Administration, Central Federal Lands Highway Division, Lakewood, CO, Publication No. FHWA-IF-04-021. http://www.cflhd.gov/resources/agm.

[27] Singha, K. and Gorelick, S.M. (2005) Saline Tracer Visualized with Three-Dimensional Electrical Resistivity Tomography: Field-Scale Spatial Moment Analysis. Water Resources Research, 41, W05023. https://doi.org/10.1029/2004WR003460

[28] Stewart, M.T. (1982) Evaluation of Electromagnetic Methods for Rapid Mapping of 
Salt-Water Interfaces in Coastal Aquifers. Groundwater, 20, 538-545.

https://doi.org/10.1111/j.1745-6584.1982.tb01367.x

[29] Open EI, Geothermal Energy (2015) Exploration Technique: Direct-Current Resistivity Survey. http://en.openei.org/wiki/Direct-Current_Resistivity_Survey

[30] Ixblue (2014) Delph Seismic Interpretation.

http://delph.ixblue.com/seismic/interpretation/ 